University of Wollongong

Research Online

Faculty of Engineering and Information

Faculty of Engineering and Information

Sciences - Papers: Part B

Sciences

2017

\title{
Site-specific atomic-scale characterisation of retained austenite in a strip cast TRIP steel
}

\section{Zhiping Xiong}

University of Science And Technology Beijing, zx868@uowmail.edu.au

Ahmed A. Saleh

University of Wollongong, asaleh@uow.edu.au

Ross Marceau

Deakin University

A S. Taylor

Deakin University

N E. Stanford

Monash University

See next page for additional authors

Follow this and additional works at: https://ro.uow.edu.au/eispapers1

Part of the Engineering Commons, and the Science and Technology Studies Commons

Research Online is the open access institutional repository for the University of Wollongong. For further information contact the UOW Library: research-pubs@uow.edu.au 


\title{
Site-specific atomic-scale characterisation of retained austenite in a strip cast TRIP steel
}

\author{
Abstract \\ Knowledge of carbon content in retained austenite (RA) with different neighbouring phases is essential to \\ understand the chemical stability of RA, which is useful for microstructure tuning of transformation- \\ induced plasticity (TRIP) steels. The present study investigates different morphologies and chemical \\ compositions of RA by correlating electron backscattering diffraction, transmission electron microscopy \\ and atom probe tomography. The effect of neighbouring phases, such as polygonal ferrite, bainitic ferrite \\ lath, ferrite in granular bainite and carbides, on the carbon content in the RA is investigated. The results \\ reveal that the film RA morphology does not always have a higher carbon content than the blocky RA; as \\ coarse RA sometimes displays a higher carbon content than the fine RA films or islands depending on the \\ neighbouring phases. The diffusion of carbon and manganese between austenite and ferrite in bainitic \\ ferrite/granular bainite has been explained according to either diffusionless and/or diffusional \\ mechanism of bainitic ferrite formation followed by tempering.

\section{Disciplines} \\ Engineering | Science and Technology Studies

\section{Publication Details} \\ Xiong, Z. P., Saleh, A. A., Marceau, R. K. W., Taylor, A. S., Stanford, N. E., Kostryzhev, A. G. \& Pereloma, E. V. \\ (2017). Site-specific atomic-scale characterisation of retained austenite in a strip cast TRIP steel. Acta \\ Materialia, 134 1-15.
}

\section{Authors}

Zhiping Xiong, Ahmed A. Saleh, Ross Marceau, A S. Taylor, N E. Stanford, Andrii Kostryzhev, and Elena V. Pereloma 


\title{
Site-specific atomic-scale characterisation of retained austenite in a strip cast TRIP steel
}

\author{
Z.P. Xiong ${ }^{1 *}$, A.A. Saleh ${ }^{1}$, R.K.W. Marceau ${ }^{2}$, A.S. Taylor ${ }^{2}$, N.E. Stanford ${ }^{3}$, A.G. Kostryzhev ${ }^{1}$, E.V. \\ Pereloma $^{1,4}$ \\ ${ }^{1}$ School of Mechanical, Materials and Mechatronic Engineering, University of Wollongong, \\ Wollongong, NSW 2522, Australia \\ ${ }^{2}$ Deakin University, Institute for Frontier Materials, Geelong, VIC 3216, Australia \\ ${ }^{3}$ Department of Materials Science and Engineering, Monash University, Clayton, Victoria 3800, \\ Australia \\ ${ }^{4}$ Electron Microscopy Centre, University of Wollongong, Wollongong, NSW 2519, Australia
}

Abstract: Knowledge of carbon content in retained austenite (RA) with different neighbouring phases is essential to understand the chemical stability of RA, which is useful for microstructure tuning of transformation-induced plasticity (TRIP) steels. The present study investigates different morphologies and chemical compositions of RA by correlating electron backscattering diffraction, transmission electron microscopy and atom probe tomography. The effect of neighbouring phases, such as polygonal ferrite, bainitic ferrite lath, ferrite in granular bainite and carbides, on the carbon content in the RA is investigated. The results reveal that the film RA morphology does not always have a higher carbon content than the blocky RA; as coarse RA sometimes displays a higher carbon content than the fine RA films or islands depending on the neighbouring phases. The diffusion of carbon and manganese between austenite and ferrite in bainitic ferrite/granular bainite has been explained according to either diffusionless and/or diffusional mechanism of bainitic ferrite formation followed by tempering.

Keywords: Retained austenite; Carbon content; Atom probe tomography; Isothermal bainite transformation; Morphology. 


\section{Introduction}

Transformation-induced plasticity (TRIP) steels exhibit microstructures comprising polygonal ferrite (PF), bainitic ferrite (BF), granular bainite (GB), retained austenite (RA) and martensite (M). BF comprises ferrite laths with inter-lath RA films; whereas, GB consists of irregular-shaped ferrite with dispersed blocky RA and/or M/RA constituent [1, 2]. TRIP steels display an outstanding combination of strength and formability due to the multi-phase microstructure and the TRIP effect, which arises from RA-to-martensite transformation during straining $[2,3]$.

The resistance of RA transformation to martensite, namely its stability, is a key factor for mechanical property control [3-6]. Therefore, the RA stability has been intensely studied with respect to its carbon (C) content [2, 7], morphology [5], size [8], orientation [9, 10] and neighbouring phases [11, 12] using step-wise straining electron backscattering diffraction (EBSD) [8], electron probe microanalysis [13], neutron diffraction [14], synchrotron X-ray diffraction [15, 16], transmission electron microscopy (TEM) and atom probe tomography (APT) [17, 18]. The general results can be summarised as follows. First, a certain intermediate $\mathrm{C}$ content in RA should be maintained to maximise the contribution of the TRIP effect to elongation. Here a C content that is too high leads to an incomplete transformation during straining, whereas a C content that is too low results in an early transformation of RA to martensite $[2,7,19,20]$. Second, blocky RA transforms to martensite during the early stage of deformation, whereas film RA shows a low tendency for martensite transformation even until fracture [4, 6, 8]. Third, an increase in the RA grain size leads to early transformation due to availability of a greater number of martensite nucleation sites (such as slip steps and stacking faults) [8]. Fourth, when the RA exhibits an orientation facilitating its deformation, it will result in an early RA-to-martensite transformation [9, 10, 21]. Lastly, there is contradictory evidence with respect to the effect of neighbouring phases on the RA stability. While some studies reported that the film RA between BF laths is more stable than the RA surrounded by PF due to high C content and stress shielding by BF laths [22, 23], Tomota et al. [14] pointed out that the RA enclosed by PF is more stable because of stress relaxation. 
It is highlighted that neighbouring phases not only determine the RA morphology but also affect its $\mathrm{C}$ content and stress partitioning. Thus, careful attention should be paid to the effect of neighbouring phases, which has not been systematically investigated so far $[4,9,11,19$, 22]. APT is a powerful characterisation technique for chemical composition analysis and has previously been applied for determination of C content in RA. However, in the majority of cases, unless APT was correlated with EBSD/TEM analysis [24, 25], the RA morphology and its neighbouring phases could not be directly determined from APT but were assumed based on comparison with TEM observations $[7,8,17,26]$. In addition to this drawback, RA and martensite cannot be distinguished in APT experiments because RA transforms to martensite due to the low testing temperature $[17,26]$. To overcome the former two issues, a site-specific investigation is carried out in the present study by correlating EBSD, TEM and APT.

Moreover, APT can also provide insight into the elemental redistribution across the interfaces and thus provide an indication of the mechanisms of phase transformation. For example, the observed substitutional solute spikes (such as $\mathrm{Mn}$ and $\mathrm{Si}$ ) at the interface between austenite and BF lath in a high-carbon TRIP steel, was explained by the local equilibrium, negligible partitioning (LENP) mode where redistribution of the substitutional solute elements is allowed [18]. Alternatively, the absence of substitutional elements redistribution between austenite and BF lath was attributed to diffusionless transformation of BF [27, 28].

It is well known that the transformation mechanism of bainite (diffusional versus diffusionless) has been debated for a long time. During the growth of bainite, the theory of diffusionless transformation suggests that there is no C diffusion [29], while the diffusional transformation considers $\mathrm{C}$ redistribution at the migrating austenite/ferrite interface [30, 31]. However, these two mechanisms assume that substitutional solutes do not redistribute at the austenite/ferrite interface during the growth of bainite [29, 30]. Recently, Chen et al. proposed the so-called Gibbs energy balance (GEB) approach in order to evaluate the effect of alloying elements on the bainite growth [32, 33]. The approach considers Gibbs energy 
dissipation due to the alloying element diffusion inside the interface.

Depending on the time of BF formation during isothermal bainite transformation (IBT), the GEB approach predicts three growth modes in the sequence of paraequilibrium (PE), negligible partitioning (NP) and partitioning (P) [32-35]. When the transformation kinetics of austenite-to-bainite exhibits a fast growth mode at an early stage, there is no substitutional solute diffusion and the transformation is only controlled by $\mathrm{C}$ diffusion under PE condition. When the kinetics turns to a slow growth mode due to the $\mathrm{C}$ enrichment in austenite, and in turn a reduced driving force, the bainite transformation follows NP condition where the substitutional solute diffusion inside the austenite/ferrite interface is promoted, resulting in solute segregation. The bainite transformation at the very late stage proceeds under the $\mathrm{P}$ condition where the growth of bainite requires substitutional solute diffusion inside the austenite, leading to the formation of solute segregations [18, 32, 36]. However, to date, the corresponding experimental observations of the above three growth modes have not been provided. Therefore, in the current study, several interfaces between austenite and BF laths or ferrite in GB were investigated using site-specific APT characterisation in order to elucidate the diffusion behaviour of substitutional solute elements in light of the GEB approach.

With the above outlook in mind, the present study is the first to experimentally clarify and systematically analyse the effect of neighbouring phases on the RA morphology and its C content in a strip cast TRIP steel. Following this, some of the general conclusions reported in previous studies, with respect to the size and carbon content of RA, are disputed and new evidence is provided. Based on the GEB approach, the analysis of substitutional solute element distributions across the interfaces between austenite and BF laths or ferrite in GB, suggests a PE growth model for GB and BF, and NP or P growth model for BF formed at later stages. Diffusionless model of BF formation followed by tempering can also explain the observed substitutional elements partitioning with the exception of one case.

\section{Experimental details}

As-cast samples were produced at Deakin University using a dip tester, which can simulate 
rapid cooling during solidification when liquid steel contacts twin rolls in strip casting [37, 38]. Post deformation (i.e. rolling) was not applied to these samples. The chemical composition of the present TRIP steel is listed in Table 1 in weight and atomic percent.

Table 1 . The chemical composition of the studied strip cast TRIP steel.

\begin{tabular}{cccccccc}
\hline & $\mathrm{C}$ & $\mathrm{Si}$ & $\mathrm{Mn}$ & $\mathrm{Al}$ & $\mathrm{Cu}$ & $\mathrm{Cr}$ & $\mathrm{P}$ \\
\hline wt.\% & 0.172 & 1.520 & 1.610 & 0.0266 & 0.0153 & 0.195 & 0.00440 \\
at.\% & 0.782 & 2.957 & 1.601 & 0.0539 & 0.0132 & 0.205 & 0.00776 \\
\hline
\end{tabular}

The quench-deformation dilatometer (Dilatronic III, Theta Industries) was used for heat treatment. The samples $\left(14 \times 6 \mathrm{~mm}^{2}\right.$ and $\sim 1 \mathrm{~mm}$ thickness) were heated to $1250{ }^{\circ} \mathrm{C}$ and held for $300 \mathrm{~s}$ in order to simulate the prior austenite grain structure $(80 \pm 27 \mu \mathrm{m})$ inherent in strip casting. Cooling at $30{ }^{\circ} \mathrm{C} / \mathrm{s}$ to $670{ }^{\circ} \mathrm{C}$ followed by $90 \mathrm{~s}$ holding led to the formation of a $0.55 \pm 0.06$ ferrite fraction. Subsequently, the samples were cooled at $50{ }^{\circ} \mathrm{C} / \mathrm{s}$ to $400{ }^{\circ} \mathrm{C}$, held for $900 \mathrm{~s}$ followed by helium quenching to room temperature. A $0.045 \pm 0.003$ fraction of RA with an average $C$ content of $1.23 \pm 0.01$ wt. \% (5.39 at. \%) was determined from the X-ray diffraction (XRD) data (X'pert-Pro MRD goniometer, PANalytical). The austenite fraction was analysed using direct comparison method while its carbon content was calculated using austenite lattice parameter according to an empirical equation [39]. Further details of the heat treatment procedure and XRD analysis are given in Ref. [39].

Thin foils ( $\phi 3 \mathrm{~mm}$ discs) were produced by wire-cutting the sample through the thickness, mechanical polishing to $80 \mu \mathrm{m}$ in thickness and twin-jet electropolishing (TenuPol-5, Struers) using an electrolyte containing 10 vol. \% perchloric acid in methanol. EBSD was carried out on these thin foils using a field emission gun - scanning electron microscope (FEG - SEM) (JSM-7001F, JEOL) fitted with a Nordlys-II(S) EBSD detector, operating at $15 \mathrm{kV}$ accelerating voltage and $~ 5.1 \mathrm{nA}$ probe current, using a step size of $0.04 \mu \mathrm{m}$. The EBSD maps returned an overall indexing rate of $\sim 98 \%$, ensuring reliable identification of RA without the need to apply any post-processing clean-up routines. The microstructures were also characterised using a scanning transmission electron microscope (JEM-ARM200F, JEOL) operating at $200 \mathrm{kV}$. Electron energy loss spectroscopy (EELS) was carried out using a step size of $11 \mathrm{~nm}$, a collection semi-angle of $8.0 \mathrm{mrad}$ and a convergence semi-angle of 24.5 
mrad. The size of PF, second phase region and blocky RA was calculated as equivalent circle diameter (ECD). Noticeably, the ECD and thickness of film RA were determined based on the two-dimensional micrographs due to the absence of three-dimensional information, although these measurements could be evaluated in three-dimensional space using a proportional relationship between two-dimensional and three-dimensional values [40].

$\mathrm{a}$

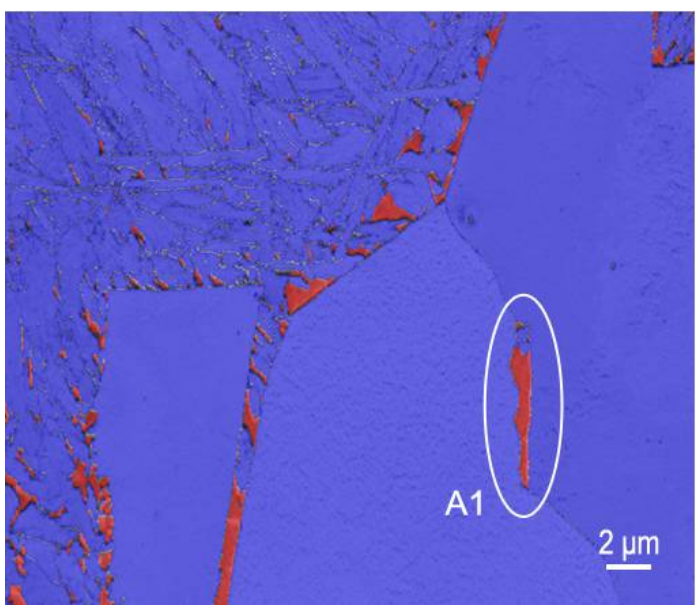

b

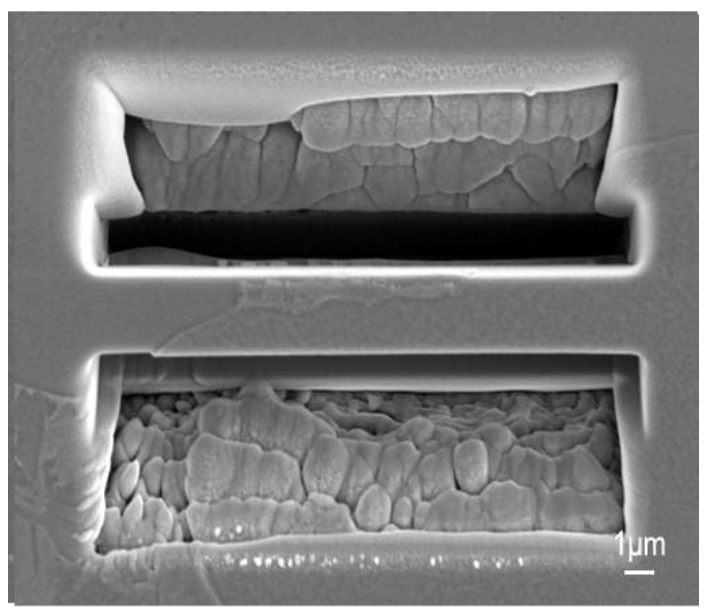

Figure 1. Specific microstructure characterisation by correlation of EBSD and APT: (a) EBSD phase map (red = fcc and blue = bcc) overlaid on band contrast and (b) lift-out preparation from the area indicated by the white oval in (a).

Following phase identification from the EBSD maps, atom probe specimens were prepared by the site-specific lift-out method $[41,42]$ as briefly presented in Figs. 1(a, b), using a dual-beam focused ion beam (FIB)/SEM instrument (Quanta 3D, FEI), with the final annular FIB milling stage operating at $8 \mathrm{kV}$ and $25 \mathrm{pA}$. APT experiments were undertaken using a local electrode atom probe (LEAP $4000 \mathrm{HR}$, Cameca Instruments) operating at a pulse repetition rate of $200 \mathrm{kHz}, 20 \%$ pulse fraction, temperate set-point of $-213{ }^{\circ} \mathrm{C}$ and target detection rate of $0.5 \%$ ( 0.05 ions per pulse). The data reconstruction and analysis were carried out using the IVAS 3.6.8 software (Cameca Instruments). The compositions of various phases were determined from bulk measurements of the volumes located far from interfaces and without any visible clusters, precipitates or solute segregations to planar defects. Interfaces were visually highlighted using iso-concentration surfaces, created using a voxel size of $1 \times 1 \times 1 \mathrm{~nm}^{3}$ and a delocalisation of $3 \times 3 \times 1.5 \mathrm{~nm}^{3}$, where the threshold iso-concentration value 
was chosen as the midpoint of difference in $\mathrm{C}$ content between the adjacent phases. A minimum of 20 atoms was used for cluster detection in order to eliminate random fluctuations. The maximum separation distance method was used for cluster-finding, with a maximum distance of $1 \mathrm{~nm}$ and a grid spacing of $0.1 \mathrm{~nm}$ [43]. The Guinier radii $\left(r_{G}\right)$ of clusters were calculated from gyration radii $\left(l_{g}\right)$ using the following equation [43]: $r_{G}=\sqrt{\frac{5}{3}} l_{g}$

\section{Results}

3.1 Correlation of microstructure using transmission electron microscopy and electron backscattering diffraction

A detailed microstructure characterisation for the studied processing condition has been reported elsewhere [39]. Here, it is worth reminding that the microstructure after holding at $400{ }^{\circ} \mathrm{C}$ for $900 \mathrm{~s}$ was comprised of $0.55 \pm 0.06$ fraction of PF and $0.045 \pm 0.003$ fraction of RA, in addition to GB, BF, and a small amount of martensite (Figs. 2(a-c)) and Widmanstätten ferrite [39]. Hereafter, the islands within polygonal ferrite grains containing GB and/or BF are defined as second phase regions. The average sizes of PF and second phase regions were $17 \pm 10$ and $21 \pm 24 \mu \mathrm{m}$, respectively [39].

The EBSD (Figs. 1(a), 2(a) and 3) and corresponding TEM observations (Figs. 2(b-e)) were used to characterise face-centred cubic (fcc) and body-centred cubic (bcc) phases. Various morphologies of RA, defined by its shape and neighbouring phases, were found in the present TRIP steel: (1) blocky RA enclosed by PF (Fig. 3(a)); (2) blocky RA within GB or adjacent to the PF/second phase region interface (Figs. 2(a) and 3); (3) blocky RA between bainitic packets (marked by dashed lines in Fig. 2(e)); (4) blocky RA present in an austenite/martensite constituent (Fig. 2(b)); (5) film RA between BF laths (Figs. 2(c, d) and $3(a, b))$. These five types of RA were also reported by other researchers [2, 9, 22]. In addition, the Kurdjumov-Sachs orientation relationship $\left(\{110\}_{\text {bcd }} / /\{111\}_{\text {fcc }},\langle 111\rangle_{\text {bcc }} / /\langle 101\rangle_{\text {fcc }}\right)$ [44] was observed between RA and martensite (Fig. 2(b)) or BF lath (Fig. 2(c)). It is noted that some nano-sized RA laths that are clearly identified using TEM (c.f. Figs. 2(a) and (d)) were not 
possible to detect via EBSD due to its spatial resolution limitations.

$\mathrm{a}$

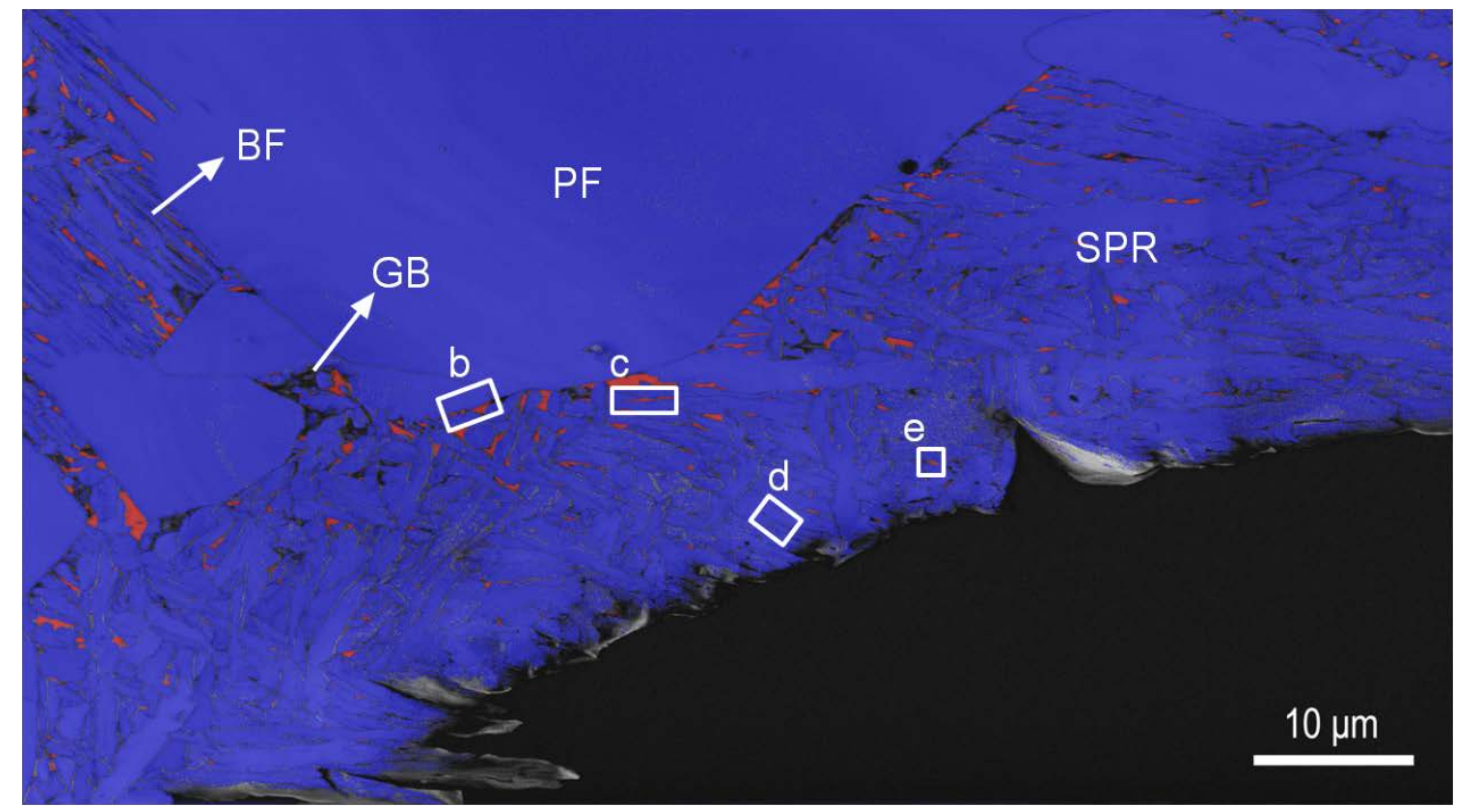

b

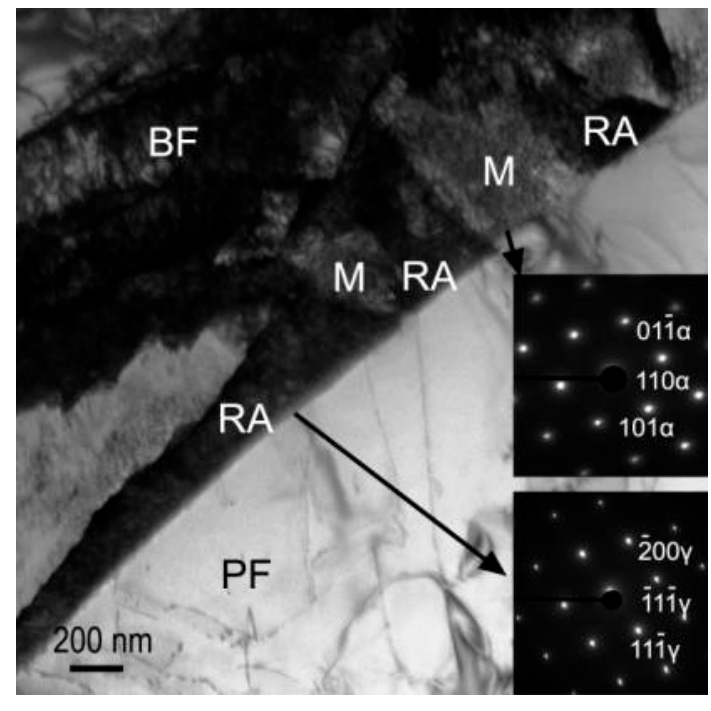

C

d

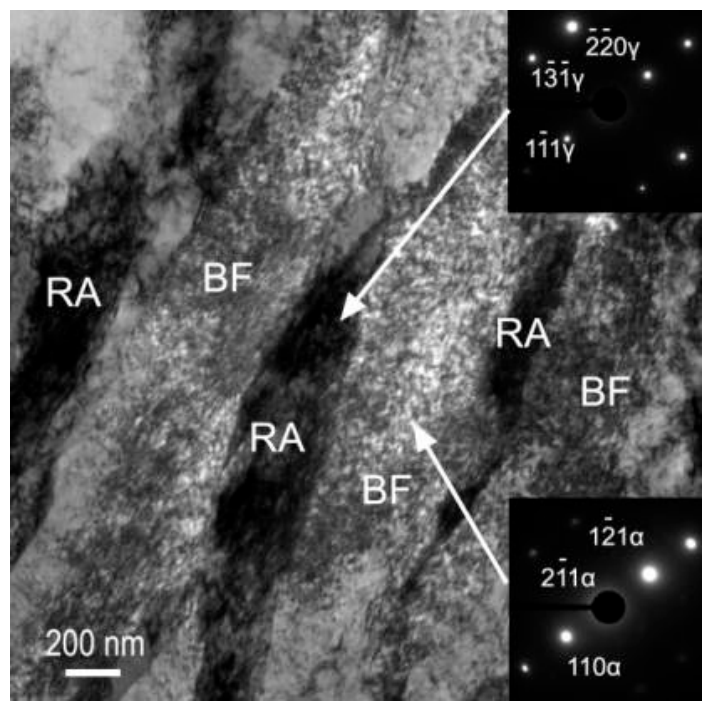

e 

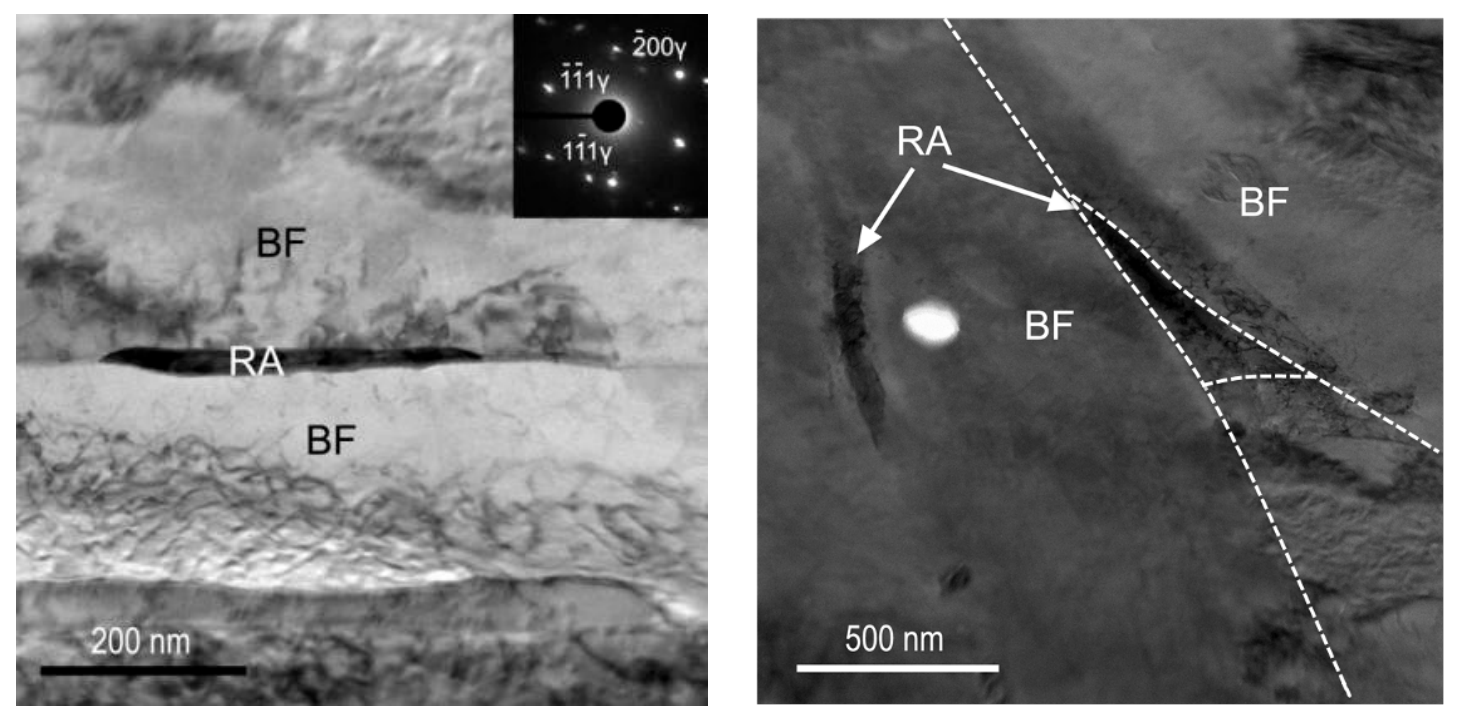

Figure 2. (a) EBSD phase map (red = fcc and blue = bcc) overlaid on band contrast (the black region at the right lower corner corresponds to the hole in the twin-jet electropolished foil) and (b, c, d, e) correlated TEM microstructures. (b) Blocky retained austenite and martensite adjacent to the polygonal ferrite/second phase region interface (the zone axis of insets is (011) $\gamma$ and (111) $)_{\alpha}$, respectively); (c, d) film retained austenite between bainitic ferrite laths (the zone axis of (c) insets is $(\overline{1} 12)_{\gamma}$ and $(\overline{1} 13)_{\alpha}$; the zone axis of (d) inset is (001) $\gamma$ ); (e) small blocky retained austenite between bainitic packets (the dashed lines showed the boundaries of three bainitic packets). $P F$ is polygonal ferrite, SPR is second phase region, $G B$ is granular bainite, $B F$ is bainitic ferrite, $M$ is martensite and $R A$ is retained austenite.

\subsection{Atom probe tomography study correlated with electron backscattering diffraction}

Figs. 1(a) and 3 show representative EBSD maps that were used to define the lift-outs for APT specimen preparation. "F”, “B” and “A” stand for film RA between BF laths (F1 - F3), blocky RA adjacent to PF (B1, B2, B4 and B5) or present in GB (B3), and blocky RA among PF (A1 and A2), respectively. Examples of RA atom maps are shown in Figs. 4 - 7. Based on the total number of ions collected from the volume free from any visible solute segregation, the chemical compositions of RA were calculated and are listed in Table 2. The observed C contents in RA are consistent with those published by many researchers [7, 8, 17, 26, 27]. For example, Timokhina et al. reported 3.8 at. \% C in blocky RA and 6.5 at. \% C in film RA in Fe-1.2C-3.8Si-1.9Mn-0.17Mo (at. \%) TRIP steel [26], and 1.5 - 7.5 at. \% C in film RA in bainitic steel (3.5 C-2.9 Si-1.9 Mn-1.0 Cr-0.13 Mo-2.1 Al-1.4 Co (at. \%)) [7]. 

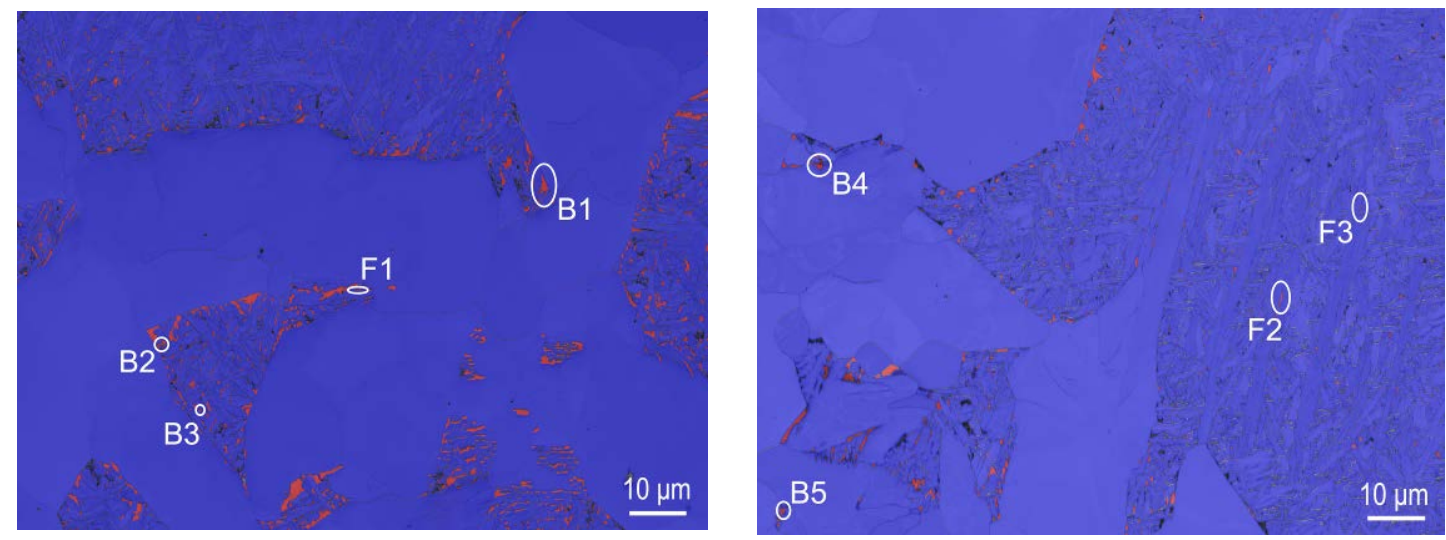

Figure 3. (a, b) Representative EBSD phase maps (red = fcc and blue = bcc) overlaid on band contrast showing the regions (white markers) used for the correlative APT study.

As seen in Table 2, the C content in the film RA (F1 - F3) increased from 3 to 6.36 at. \%, with a decrease in the size of second phase region from 83.8 to $25.6 \mu \mathrm{m}$. In the blocky RA adjacent to the PF (B1, B2 and B4) or present in GB (B3), the C content also increased from 5.10 to 6.08 at. \% with a decrease in the size of second phase region from $>50.8$ to $7.4 \mu \mathrm{m}$. On the other hand, the B5 sample exhibited a lower C content of 5.73 at. \% with a further decrease in the size of the second phase region down to $1.3 \mu \mathrm{m}$. The $\mathrm{C}$ contents $(6.23-6.78$ at. \%) in the blocky RA among PF (A1 and A2) were relatively higher than those in the blocky RA adjacent to the PF (B1, B2 and B4) or present in the GB (B3). Noticeably, the film RA did not always have a higher C content than the blocky RA (such as F2 and B1 - B5). With a decrease in the RA grain size, the $\mathrm{C}$ content did not always increase (such as in A1 and A2).

Table 2. Chemical compositions of retained austenite (at. \%) determined from atom probe tomography data, and the equivalent circle diameter (ECD)/thickness of retained austenite together with the ECD of the second phase region corresponding to its location (determined from EBSD). Iron is balance.

\begin{tabular}{ccccccccc}
\hline & & & & & & & & \multicolumn{2}{c}{ Second phase } \\
No. & $\mathrm{C}$ & $\mathrm{Mn}$ & $\mathrm{Si}$ & $\mathrm{Cr}$ & $\mathrm{Ms},{ }^{\circ} \mathrm{C}$ & $\begin{array}{c}\text { Thickness, } \\
\mu \mathrm{m}\end{array}$ & $\begin{array}{c}\text { ECD, } \\
\mu \mathrm{m}\end{array}$ & $\begin{array}{c}\text { region size, } \\
\mu \mathrm{m}\end{array}$ \\
\hline F1 & $6.36 \pm 0.02$ & $1.85 \pm 0.02$ & $3.72 \pm 0.02$ & $0.38 \pm 0.01$ & -179 & 0.28 & -- & 25.6 \\
F2 & $2.17 \pm 0.05$ & $1.95 \pm 0.08$ & $3.70 \pm 0.09$ & $0.41 \pm 0.04$ & 241 & 0.24 & -- & 83.8 \\
F3 & $3.19 \pm 0.02$ & $1.76 \pm 0.02$ & $3.85 \pm 0.03$ & $0.37 \pm 0.01$ & 147 & 0.16 & -- & 83.8 \\
B1 & $5.10 \pm 0.03$ & $1.53 \pm 0.05$ & $3.69 \pm 0.03$ & $0.31 \pm 0.03$ & -34 & -- & 1.9 & $>50.8$ \\
B2 & $5.45 \pm 0.01$ & $1.60 \pm 0.02$ & $2.98 \pm 0.04$ & $0.23 \pm 0.01$ & -57 & -- & 1.1 & 25.6 \\
B3 & $5.89 \pm 0.01$ & $1.87 \pm 0.01$ & $3.84 \pm 0.01$ & $0.39 \pm 0.01$ & -131 & -- & 0.6 & 25.6 \\
B4 & $6.08 \pm 0.06$ & $2.15 \pm 0.06$ & $3.58 \pm 0.07$ & $0.46 \pm 0.03$ & -161 & -- & 1.3 & 7.4 \\
\hline
\end{tabular}




\begin{tabular}{llllllllc}
\hline B5 & $5.73 \pm 0.02$ & $1.68 \pm 0.01$ & $3.62 \pm 0.02$ & $0.35 \pm 0.01$ & -101 & -- & 1.1 & 1.3 \\
A1 & $6.23 \pm 0.01$ & $1.68 \pm 0.01$ & $3.55 \pm 0.01$ & $0.38 \pm 0.01$ & -153 & -- & 2.3 & -- \\
A2 & $6.78 \pm 0.01$ & $1.87 \pm 0.01$ & $3.83 \pm 0.01$ & $0.40 \pm 0.01$ & -226 & -- & 2.5 & -- \\
\hline
\end{tabular}

Additionally, the Mn content in the film RA (F1 - F3) was between 1.68 and 1.95 at. \% (Table 2). For the blocky RA (B1 - B4), the Mn concentration increased from 1.53 to 2.15 at. \% with a decrease in the second phase region size from $>50.8$ to $7.4 \mu \mathrm{m}$. This trend is similar to that observed for the $\mathrm{C}$ content. When the size of the second phase region further decreased to $1.3 \mu \mathrm{m}$, the Mn content in the B5 sample decreased to 1.68 at. \%. The Cr content was between 0.37 and 0.41 at. \% in the film RA and was between 0.23 and 0.46 at. \% in the blocky RA. The Si content in RA generally varied around 3.70 at. \%, which is slightly higher than the nominal Si content in the steel (Table 1), probably due to the preferential evaporation of Si [45].

\subsubsection{Film retained austenite between bainitic ferrite laths}

A representative film RA between two BF laths (location F1 in Fig. 3(a)), is shown in Fig. 4. The C, Mn and Cr atom maps clearly show the interfaces between RA and BF laths (Figs. 4(a, b, d)), due to the variations in their concentrations in RA and BF laths, whereas the Si was more homogenously distributed (Fig. 4(c)). On average, the C content (Figs. 4(a, e, f)) in RA (6.36 \pm 0.02 at. \%) was much higher than the BF laths $(0.53 \pm 0.02$ at. \%). The $\mathrm{Mn}$ and $\mathrm{Cr}$ contents (Figs. 4(e, f)) were slightly higher in RA (1.85 \pm 0.02 at. \% Mn and $0.38 \pm 0.01$ at. \% $\mathrm{Cr})$ compared to those in the BF laths $(1.68 \pm 0.07$ at. \% $\mathrm{Mn}$ and $0.28 \pm 0.03$ at. \% Cr). Since C and $\mathrm{Mn}$ are austenite stabilising elements [2, 18, 33], they partition from the BF to austenite leading to higher contents in the latter. 


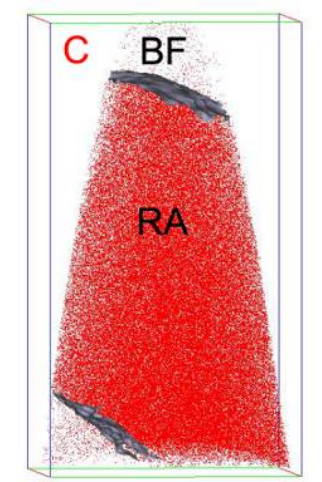

$\mathrm{e}$

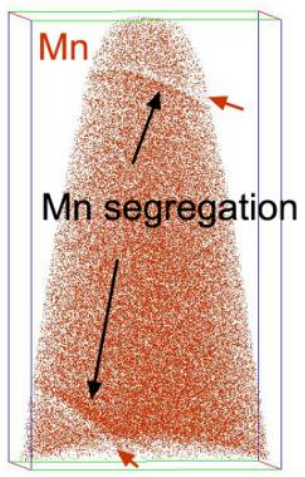

$\mathrm{f}$
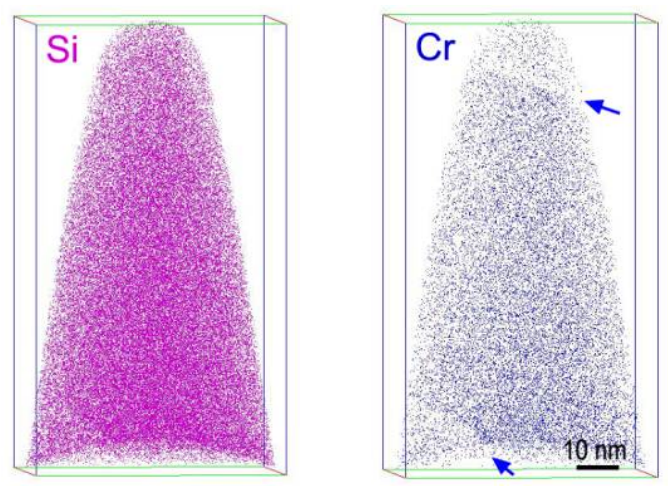
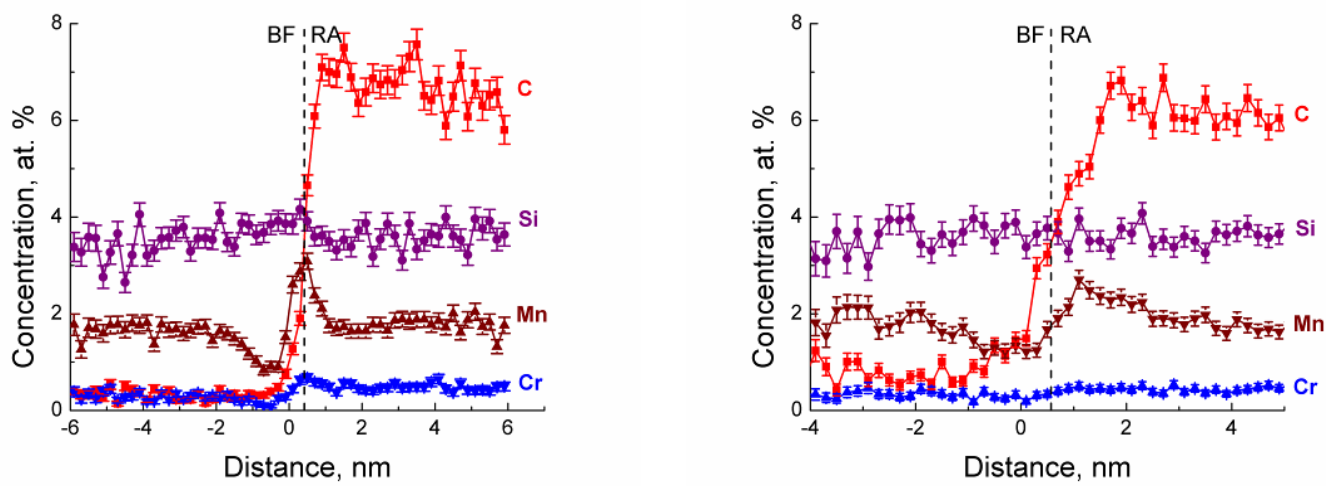

Figure 4. (a) Carbon (3.0 at. \% C iso-concentration surface is visually shown as the upper and lower interfaces with the removal of isolated fragments for clarity), (b) manganese, (c) silicon and (d) chromium atom maps (brown and blue arrows indicate the interfaces between retained austenite and bainitic ferrite laths); (e, f) proximity histograms across the (e) upper and (f) lower interfaces (dashed lines indicate the interfaces between retained austenite and bainitic ferrite laths). $R A$ is retained autenite and $B F$ is bainitic ferrite lath. The total number of analysed atoms is 72,584,277.

Chemical gradients across interfaces were revealed using proximity histograms at iso-concentration surfaces of 3.0 at. \% C (Figs. 4(e, f)). The proximity histogram across the upper interface (Fig. 4(e)) shows C, Mn and Cr concentration peaks of 7.50, 3.09 and 0.67 at. $\%$ at 1.1, 0.1 and $0.1 \mathrm{~nm}$, respectively, from the RA/BF lath interface on the RA side. The proximity histogram across the lower interface (Fig. 4(f)) shows C, Mn and Cr concentration peaks of $6.82,2.71$ and 0.5 at. \% at $1.3,0.5$ and $0.5 \mathrm{~nm}$, respectively, from the RA/BF lath interface on the RA side. The pronounced $\mathrm{Mn}$ and $\mathrm{Cr}$ enrichments at the RA/ferrite interface (Figs. 4 (e, f) and 5(e)) are beyond the limits of $\pm 2 \sigma_{\mathrm{r}}$ interval. Therefore, these fluctuations can be regarded as real effects and are not APT reconstruction artefacts. Noticeably, the Mn segregation adjacent to the interface could lead to local straining due to the substitution of Fe with Mn [13], which would deteriorate the RA stability. 


\subsubsection{Blocky retained austenite in granular bainite}

A representative blocky RA in GB (location B4 in Fig. 3(b)) is shown in Fig. 5. The C, Mn and $\mathrm{Cr}$ atom maps clearly show the interface between the RA and ferrite in GB, due to the variation in their concentrations across the interface (Figs. 5(a, b, d)). Alternatively, the Si was more homogenously distributed in both the RA and ferrite in GB as seen in Figs. 5 (c, e). On average, the $\mathrm{C}, \mathrm{Mn}$ and $\mathrm{Cr}$ contents in RA (6.08 $\pm 0.06,2.15 \pm 0.06$ and $0.46 \pm 0.03$ at. \%, respectively) were higher than those in the ferrite of GB $(0.54 \pm 0.02,1.40 \pm 0.04$ and $0.22 \pm 0.02$ at. \%, respectively). The proximity histograms calculated across the iso-concentration surface of 3.0 at. \% C (Fig. 5(e)) show C, Mn and Cr concentration peaks of 6.80, 2.66 and 0.53 at. \% at 1.4, 0.8 and $0.8 \mathrm{~nm}$, respectively, from the RA/ferrite interface on the RA side.

a

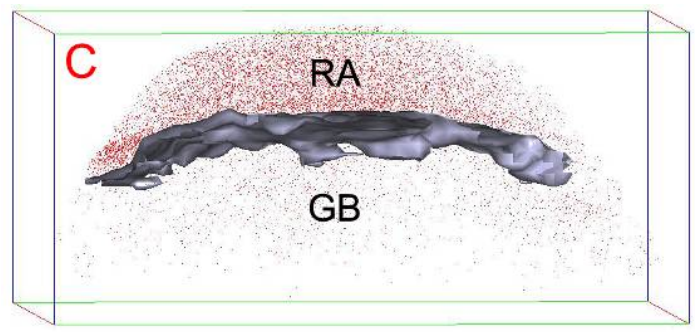

C

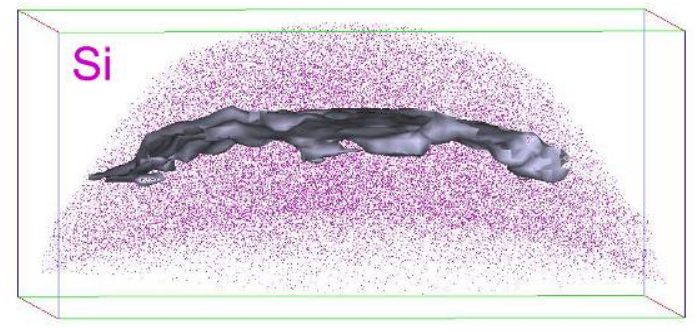

$\mathrm{b}$

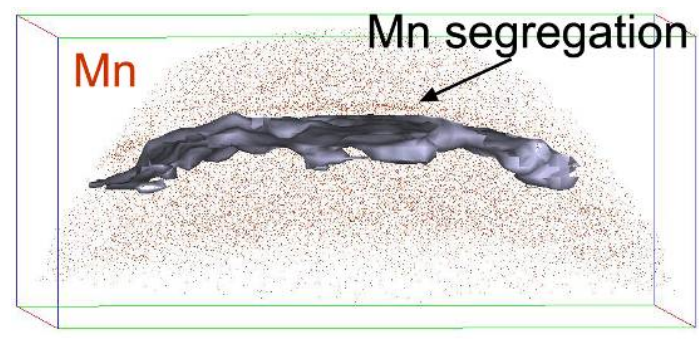

d

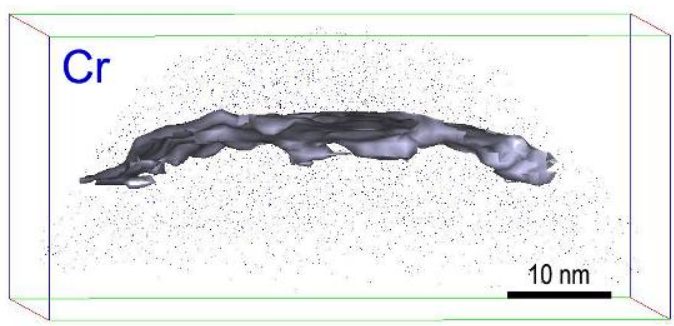

e

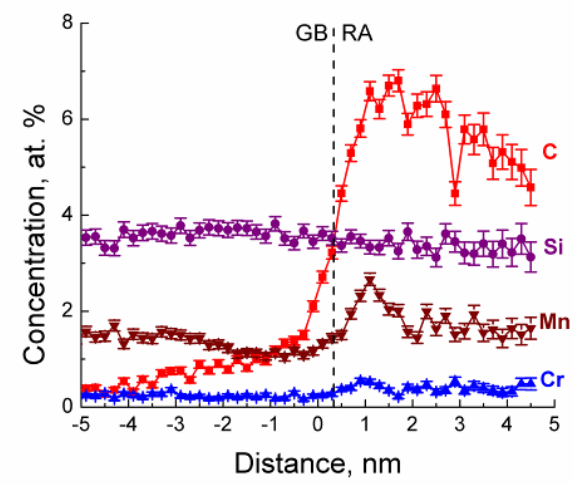


Figure 5. (a) Carbon, (b) manganese, (c) silicon and (d) chromium atom maps of granular bainite (3.0 at. \% $\mathrm{C}$ iso-concentration surface is visually shown as the interface between retained austenite and ferrite of GB with the removement of isolated fragments for clarity); (e) proximity histogram across the interface. $R A$ is retained autenite and $G B$ is ferrite in granular bainite. The total number of analysed atoms is $2,079,655$.

A representative blocky RA adjacent to the cementite (location B5 in Fig. 3(b)) is shown in Fig. 6. The $\mathrm{C}$ atom map has three distinct regions: the lowest $\mathrm{C}$ content region corresponding to ferrite in GB; the highest $\mathrm{C}$ content associated with cementite; the intermediate C content region demarcating $\mathrm{RA}$. The average $\mathrm{C}$ content was $5.73 \pm 0.02,26.07 \pm 0.18$ and $0.39 \pm 0.01$ at. \% in the RA, cementite and ferrite of GB, respectively, while the Mn content was $1.68 \pm 0.01$, $2.93 \pm 0.08$ and $1.40 \pm 0.06$ at. $\%$ in the same regions. The $1 \mathrm{D}$ concentration profile along the black arrow shown in Fig. 6(b) allowed the identification of cementite, according to the $\sim 25$ at. \% C content inherent to cementite stoichiometry [46]. In the core, cementite was enriched in $\mathrm{Mn}$ and $\mathrm{Cr}$ but depleted in Si because of its low solubility in cementite and high driving force for its removal $[18,47]$. In contrast to the present results, no silicon depletion was observed in cementite following $180 \mathrm{~s}$ holding at $500{ }^{\circ} \mathrm{C}$ for bainite formation in 0.3C-0.25Si-1.22Mn-0.14Cr steel (wt. \%) [48], and also after tempering at $200{ }^{\circ} \mathrm{C}$ for 240 hours in 0.98C-1.46Si-1.89Mn-0.26Mo-1.26Cr-0.09V steel (wt. \%) [27]. Alternatively, similar to the current work, a significant reduction in the Si content in the cementite core was detected in APT studies of cementite formation in 0.22C-1.19Si-1.53Mn-0.57Al-0.037Nb steel (wt. \%) during $1800 \mathrm{~s}$ holding at $500 \quad{ }^{\circ} \mathrm{C} \quad[17]$ and in 0.98C-1.46Si-1.89Mn-0.26Mo-1.26Cr-0.09V steel after tempering at $450{ }^{\circ} \mathrm{C}$ for $1800 \mathrm{~s}$ [49]. As pointed out by Caballero et al. [49], during the early stage of cementite formation, there was no redistribution of substitutional solutes between cementite and ferrite, suggesting that cementite was formed by PE growth. With increasing holding temperature/time, Si diffused out of the carbide, to reach an equilibrium concentration at the cementite/ferrite interface, indicating the transition from PE to local equilibrium condition. 

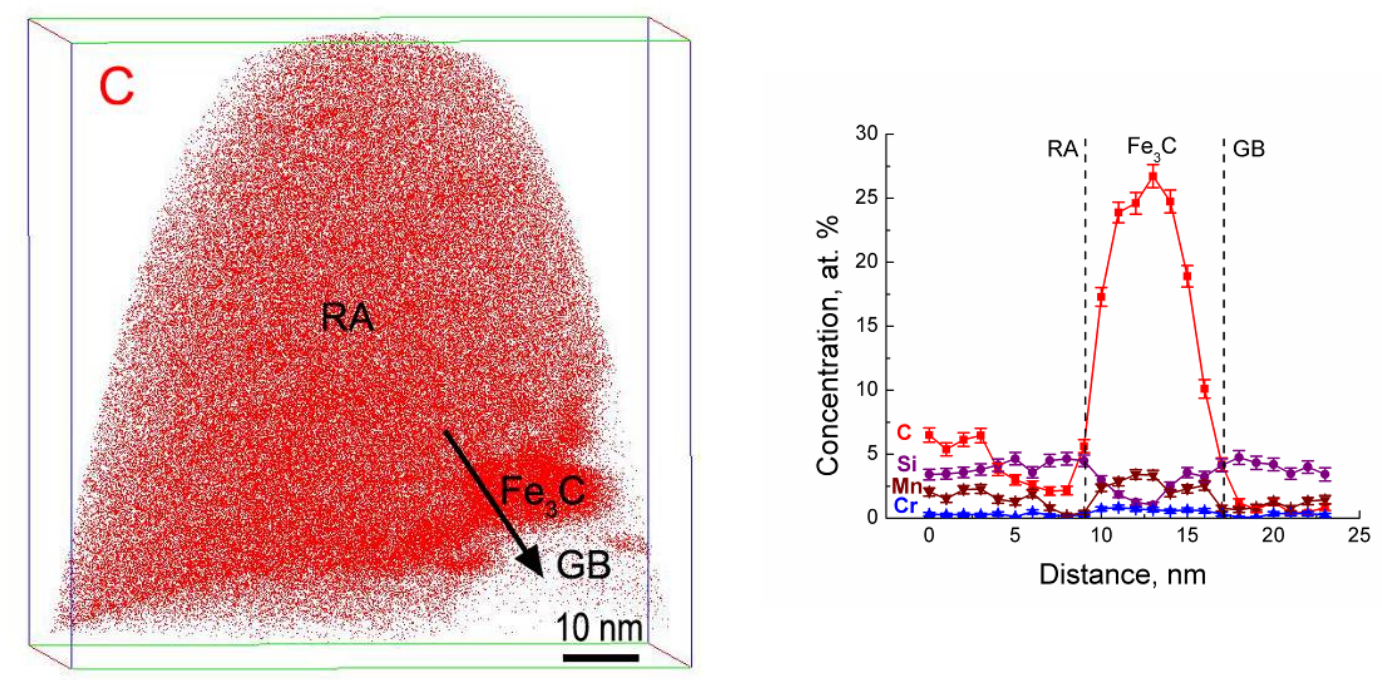

Figure 6. (a) Carbon atom map and (b) concentration profiles along the arrow in (a). $R A$ is retained austenite, $G B$ is ferrite in granular bainite and $\mathrm{Fe}_{3} \mathrm{C}$ is cementite. The total number of analysed atoms is $11,437,692$.

\subsubsection{Blocky retained austenite enclosed by polygonal ferrite}

A representative blocky RA enclosed by PF (location A1 in Fig. 1(a)) is shown by an 8.0 at. \% C iso-concentration surface in Fig. 7(a). The linear feature with high level of C (indicated by a black arrow in Fig. 7(a)) has been identified as a Cottrell atmosphere. A 1D composition profile aligned perpendicularly across this atmosphere is shown in Fig. 7(b). Here it can be seen that the dislocation only trapped $\mathrm{C}$ atoms but not substitutional solute atoms (Mn, Si and Cr), as suggested by Kalish et al. [50]. The average C content of this Cottrell atmosphere was around 7.5 at. \%. It corresponds to the saturation $C$ concentration of $6-7$ at. \% in the region of one Burgers vector around the core, which was predicted by Cochardt et al. [51]. Similarly, Timokhina et al. [52] also revealed a Cottrell atmosphere in RA using an iso-concentration surface of 7.0 at. \% C. 

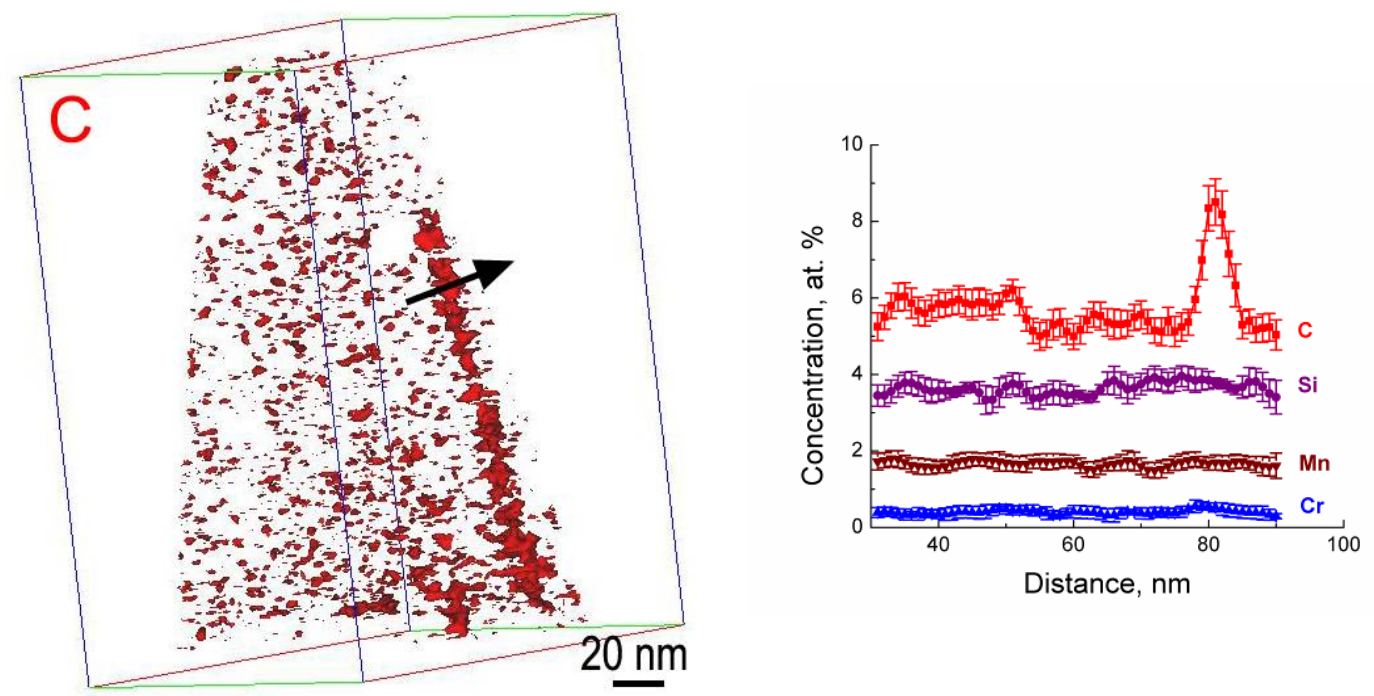

C
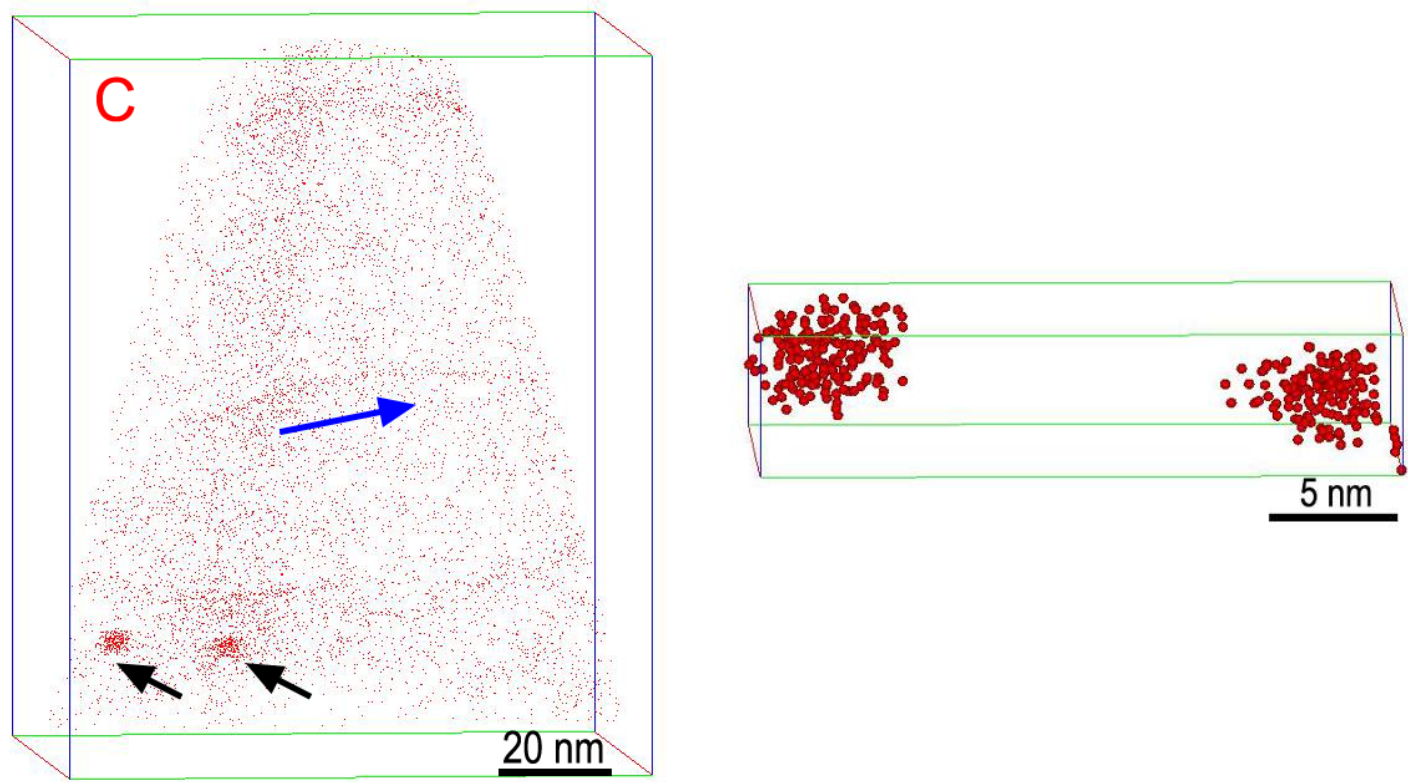

e

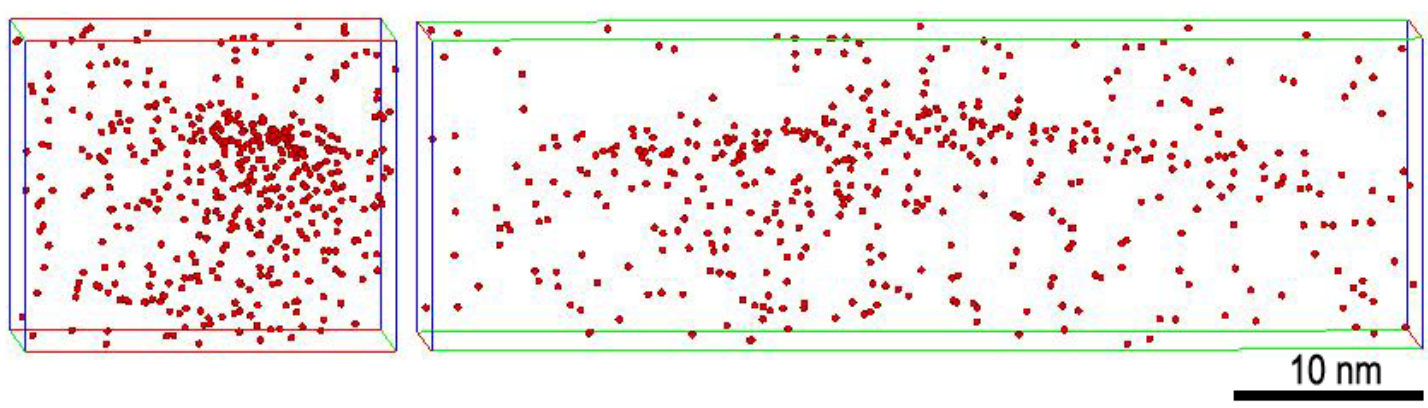


Figure 7. (a) Carbon iso-concentration surfaces at 8.0 at. \% in blocky retained austenite and (b) concentration profiles along the dark arrow in (a); (c) carbon atom map of polygonal ferrite adjacent to the blocky retained austenite shown in (a), (d) clusters indicated by dark arrows in (c) and (e) atom maps of Cottrell atmosphere parallel to the blue arrow in (c) taken in two perpendicular directions showing its rod-like shape. The matrix atoms for (d) were suppressed with the maximum separation distance of $1 \mathrm{~nm}$. The total number of analysed atoms is 30,017,388 in (a) and 23,583,341 in (c).

Fig. 7(c) depicts the $\mathrm{C}$ atom map of PF adjacent to the blocky RA shown in Fig. 7(a). The Mn, $\mathrm{Si}$ and $\mathrm{Cr}$ atom maps are not presented here as these elements have shown homogeneous distributions in PF. C clusters in this PF (indicated by two black arrows in Fig. 7(c)) are clearly visible and shown at higher magnification in Fig. 7 (d). A Cottrell atmosphere where $\mathrm{C}$ atoms are trapped along the dislocation line can also be seen in the PF, shown nearly parallel to the blue arrow in Fig. 7 (c), and at higher magnification in Fig. 7 (e). The C content was estimated to be $6.23 \pm 0.01$ and $0.03 \pm 0.002$ at. \% in RA and PF, respectively, while the Mn content was $1.68 \pm 0.01$ and $1.62 \pm 0.01$ at. \%, and the $\mathrm{Cr}$ content was $0.37 \pm 0.01$ and $0.26 \pm 0.01$ at. $\%$.

\subsubsection{Cementite adjacent to bainitic ferrite}

A limited amount of nanoscale cementite ( $2.7 \mathrm{~nm}$ thickness) was observed by APT between the BF laths and an example is given in Fig. 8(a), containing $23.39 \pm 0.06$ at. \% C. Similar to the concentration profiles shown in Fig. 6(b), the Si content in this cementite was also depleted (Fig. 8(b)). Cementite was not observed in this study in PF or ferrite in GB, among at least five APT runs for each phase. 

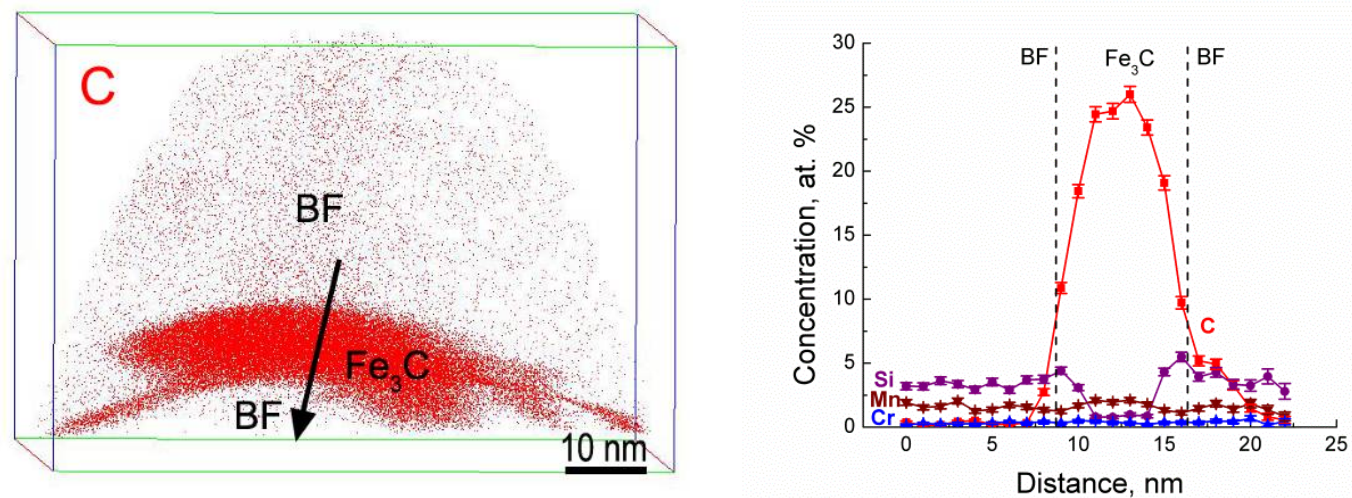

Figure 8. (a) Cementite observed between bainitic ferrite laths and (b) the corresponding concentration profiles along the dark arrow in (a). $\mathrm{BF}$ is bainitic ferrite lath and $\mathrm{Fe}_{3} \mathrm{C}$ is cementite. The total number of analysed atoms is $17,236,597$.

\subsubsection{Solute redistribution across the interface}

Solute segregation across the interfaces between RA and BF laths (Fig. 4) or RA and ferrite in GB (Fig. 5) was characterised using the following steps. The proximity histogram (similar to Fig. 4(e)) was measured from a cylindrical region of interest aligned perpendicular to the iso-concentration surface of 3.0 at. \% C (Fig. 9(a)). Subsequently, the cumulative numbers of solute atoms as a function of the cumulative number of all atoms were plotted in Fig. 9(b). Following this, the segregation region was identified by the change in linear relationship (illustrated in Fig. 9(b), using Mn as an example) such that the widths of the interfacial solute segregation were determined.

Fig. 9(c) shows the interfacial widths for $\mathrm{C}$, Mn and $\mathrm{Cr}$ for different interfaces between RA and ferrite (Figs. 4(a) and 5(a)) based on the analysis described above. According to Fig. 9(c), the relative diffusion distances of $\mathrm{Mn}$ and $\mathrm{Cr}$ with respect to the $\mathrm{C}$ interface are listed in Table 3. As can be seen, for the upper interface between RA and BF lath (Fig. 4), the Mn interface width is greater than that of the $\mathrm{C}$, whereas for the lower interface, the Mn interface width is again slightly greater than that of $\mathrm{C}$, but shifted $\sim 1.0 \mathrm{~nm}$ towards the austenite side. For the interface between RA and ferrite in GB (Fig. 5), the Mn interfacial region also moves towards the austenite side but to a slightly larger distance of $\sim 1.1 \mathrm{~nm}$. Toji et al. [25] also reported a diffusion distance of Mn less than $2 \mathrm{~nm}$ during $300 \mathrm{~s}$ holding at $400{ }^{\circ} \mathrm{C}$ in a quenched and 
partitioned steel. The Cr interface regions had similar ranges to those determined for Mn (Fig. 9(c) and Table 3). It should be noted that the distances listed in Table 3 slightly differ from those determined from the proxigram analysis in Sections 3.2.1 and 3.2.2. The former is used in the subsequent analysis, as we believe that this approach of estimating diffusion distances is more accurate due to the employed linear deviation.

$\mathrm{a}$

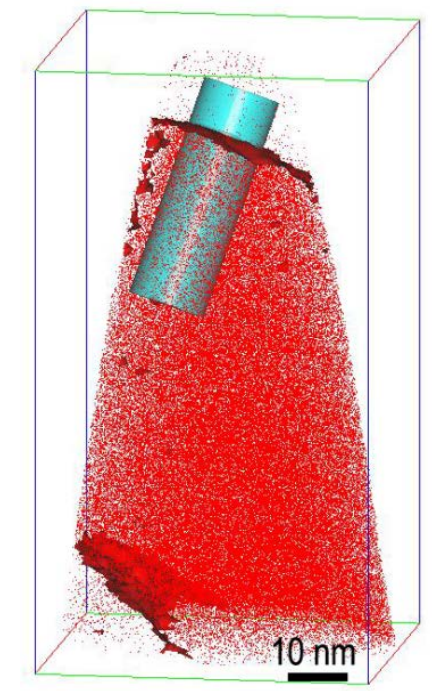

b

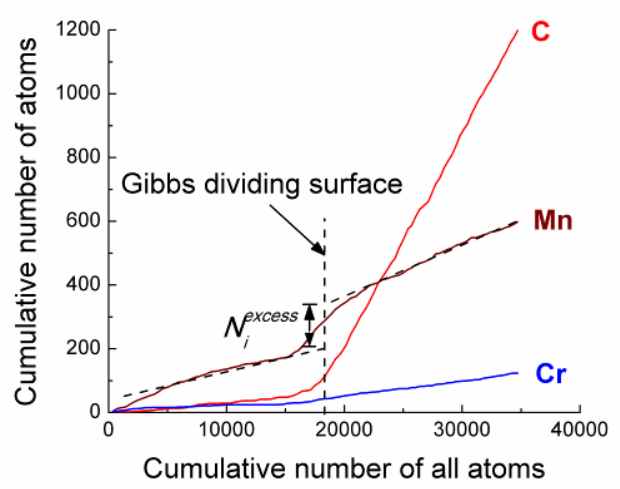

C

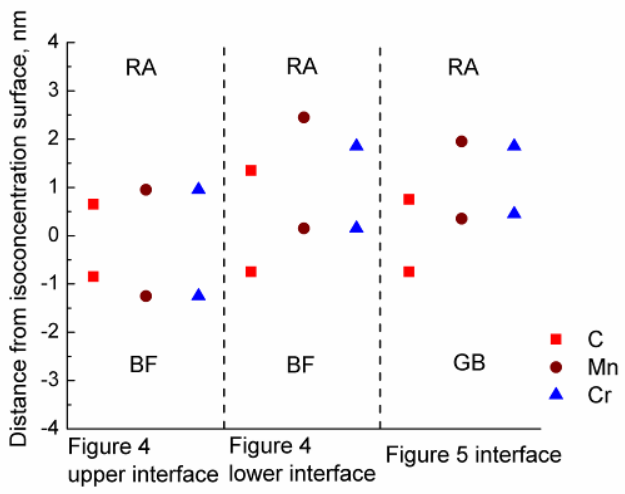

Figure 9. (a) A representative cylindrical region of interest perpendicular to the iso-concentration surface of 3.0 at. \% carbon (Figure 4(a)), and (b) corresponding integral profiles across the interface showing the cumulative number of carbon, manganese and chromium atoms as a function of the cumulative number of all atoms; (c) interface regions for carbon, manganese and chromium determined by proximity histogram analysis. $R A$ is retained austenite, $B F$ is bainitic ferrite lath and $G B$ is ferrite in granular bainite.

The Gibbsian interfacial excess of $\mathrm{Mn}$ and $\mathrm{Cr}$ (Table 3) is calculated as follows [54]: 
$\Gamma_{i}=N_{i}^{e x c e s s} / \eta A$

where $N_{i}^{\text {excess }}$ is determined as shown in Fig. 9(b), $\eta$ is the atom probe detection efficiency ( $\eta=0.42$ ), and $A$ is the selected interfacial area. The interface between RA and ferrite in GB (Fig. 5) exhibits the lowest $\Gamma_{i}$ for $\mathrm{Mn}$ and $\mathrm{Cr}$, while the upper interface between RA and BF lath (Fig. 4) has the highest $\Gamma_{i}$ for Mn and Cr. Here an increase in the diffusion lengths of Mn and $\mathrm{Cr}$ corresponds to a decrease in the Gibbsian interfacial excess. These results provide supportive evidence for the diffusion of Mn and Cr.

Table 3. The relative diffusion distance of $\mathrm{Mn} / \mathrm{Cr}$ segregation region with respect to $\mathrm{C}$ interface region and the Gibbsian interfacial excess of solutes (atoms $/ \mathrm{cm}^{2}$ ). $R A$ is retained austenite, $B F$ is baintic ferrite and $G B$ is granular bainite.

\begin{tabular}{ccccc}
\hline & \multicolumn{2}{c}{$\begin{array}{c}\text { Diffusion distance with respect to } \\
\text { carbon interface region, } \mathrm{nm}\end{array}$} & \multicolumn{2}{c}{$\begin{array}{c}\text { Gibbsian interfacial excess, } \\
\text { atoms } / \mathrm{cm}^{2}\end{array}$} \\
\cline { 2 - 5 } & $\mathrm{Mn}$ & $\mathrm{Cr}$ & $\mathrm{Mn}$ & $\mathrm{Cr}$ \\
\hline $\begin{array}{c}\text { Upper interface between RA } \\
\text { and BF lath (Figure 4) } \\
\text { Lower interface between RA } \\
\quad \begin{array}{l}\text { and BF lath (Figure 4) } \\
\text { The interface between RA and } \\
\text { ferrite in GB (Figure 5) }\end{array}\end{array}$ & 0.1 & 0.1 & $2.1 \pm 0.4 \times 10^{14}$ & $0.3 \pm 0.08 \times 10^{14}$ \\
\hline
\end{tabular}

\section{Discussion}

\subsection{Carbon partitioning}

The formation of PF, GB and BF during the two-stage heat treatment of the present TRIP steel is responsible for the $\mathrm{C}$ enrichment in austenite. First, $\mathrm{C}$ was rejected into austenite during the formation of PF (which refers to remaining austenite hereafter) upon cooling to $670{ }^{\circ} \mathrm{C}$ and holding for $90 \mathrm{~s}$ at the same temperature. Following this, the $\mathrm{C}$ enrichment in the remaining austenite continued due to the formation of GB and BF during cooling to the IBT temperature of $400{ }^{\circ} \mathrm{C}$ and holding for $900 \mathrm{~s}$. According to the APT data analysis of volumes free from any visible segregation, the average $\mathrm{C}$ content in PF and ferrite in GB/BF lath was $0.025 \pm 0.003$ and $0.43 \pm 0.099$ at. \%, respectively. The latter value is about 6 times higher than that calculated ( 0.075 at. \% [17]) based on the PE condition between austenite and ferrite. This high C content in ferrite of GB and BF lath is possibly due to the $\mathrm{C}$ atoms being trapped 
in the octahedral interstices upon diffusionless transformation [55] and/or C-Mn dipole formation [56]. Thus, the contribution of the $\mathrm{C}$ atoms rejected into the austenite from PF was much higher than that from ferrite in GB and BF lath.

Additionally, there are another two factors that could hypothetically reduce the capability of ferrite in GB and BF lath to enrich the austenite with $\mathrm{C}$ atoms. First, the dislocation density in the ferrite of $\mathrm{GB}$ and $\mathrm{BF}$ lath $\left(10^{14}-10^{15} \mathrm{~m}^{-2}[7,27,28]\right)$ is higher than that in the PF $\left(5.1 \pm 0.42 \times 10^{13} \mathrm{~m}^{-2}\right.$ [57]), leading to more $\mathrm{C}$ atoms being trapped at the dislocations and consequently less $\mathrm{C}$ atoms available for austenite enrichment. Second, the observed nanoscale cementite in the BF (Fig. 8(a)) could reduce the $\mathrm{C}$ atoms available for austenite enrichment, since $\mathrm{C}$ partitioning into austenite and carbide precipitation are competitive processes [29].

\subsection{The dependence of carbon content of retained austenite on its neighbours}

The neighbouring phases of RA were found to affect its morphology. As shown in Fig. 2, the RA surrounded by PF and/or in GB exhibited blocky shape, the RA between the BF laths displays film shape and the RA located between the BF packets is characterised by a blocky shape $[2,5,18]$. In addition, the neighbouring phases of RA have also affected its C content (Section 4.1). The formation of PF resulted in the rejection of much more C into austenite than that rejected by ferrite in GB and BF lath. Thus, the fraction of neighbouring PF around second phase regions should be first considered. For easy comparison, the fraction of neighbouring PF is defined as the ratio of the PF area and the second phase region area, by drawing a circle in the centre of the latter using a defined radius as shown in Figs. 10(a, b) for two different sizes of second phase regions. In reality, the ratio of volumes should be considered rather than the ratio of the areas. However, only two-dimensional EBSD maps were used in the present work. According to the ratio of the areas, a smaller second phase region has a higher fraction of neighbouring PF than a larger second phase region (c.f. Figs. 10(a) and (b)). Therefore, after polygonal ferrite formation, the carbon content in smaller remaining austenite region (which will transform to second phase region after bainite formation) is higher than that in the larger remaining austenite region (dot lines in Fig. 10(c)). 
After bainite transformation, compared to a larger second phase region, the amount of ferrite in $\mathrm{GB} / \mathrm{BF}$ formed in a smaller second phase region is reduced. As a result, the RA in the smaller second phase region will be effectively enriched to a greater extent due to a much larger (almost 6 times, as calculated in section 4.1) contribution of $C$ enrichment to austenite from $\mathrm{PF}$ than that from ferrite in BF/GB (solid lines in Fig 10. (c)). This corresponds to the observed increase in the $\mathrm{C}$ content in RA with the decrease in the size of second phase region (Table 2), regardless of the RA morphology being film (F1 - F3) or blocky (B1 - B4).

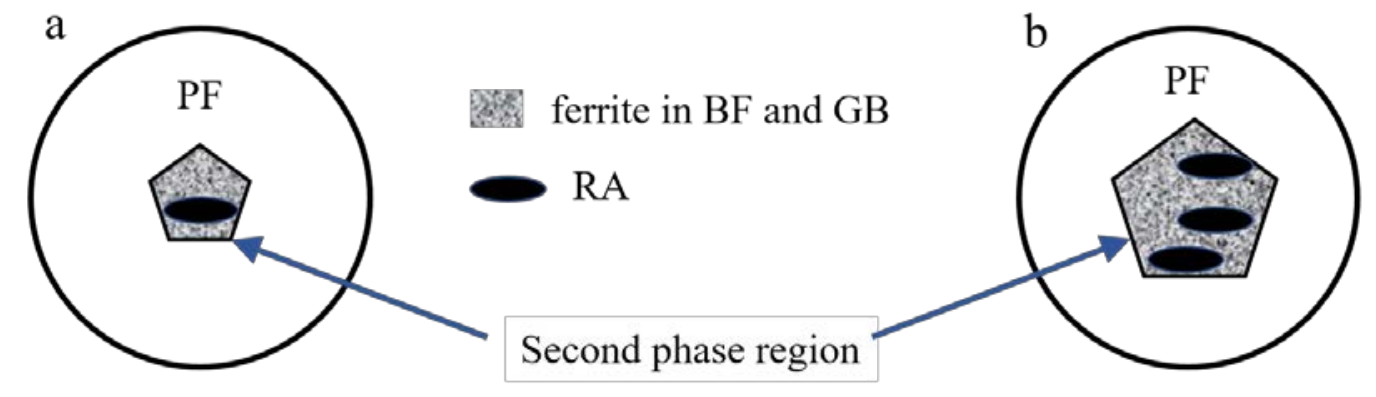

c

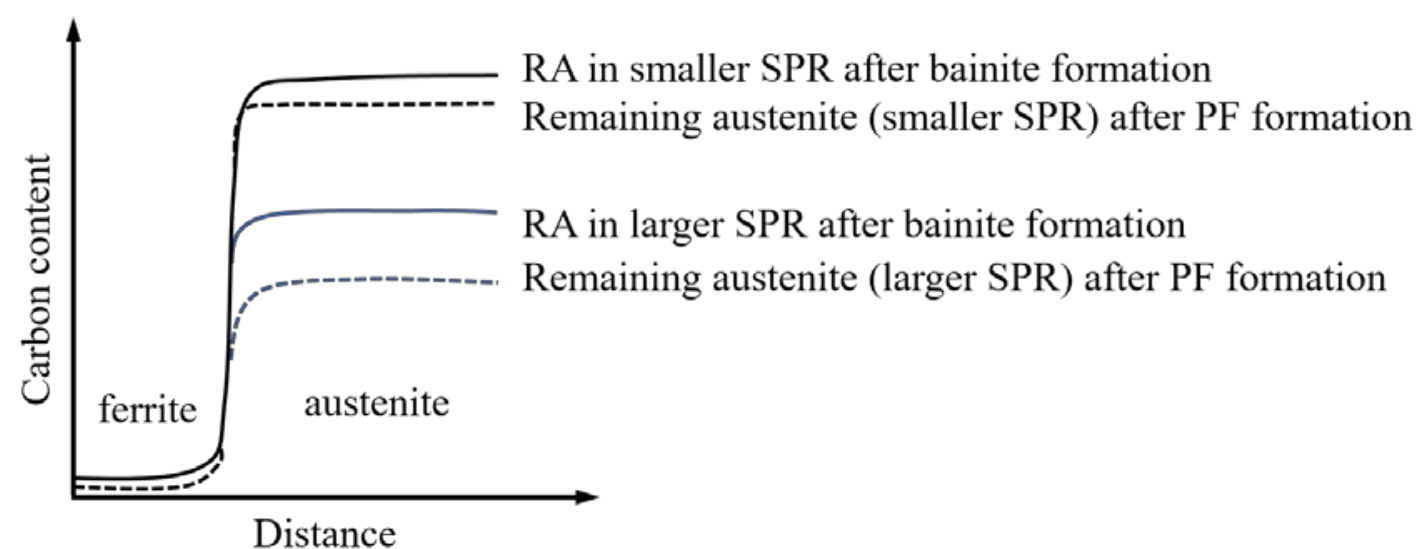

Fig. 10. Schematic comparison of neighbouring polygonal ferrite fraction in (a) smaller second phase region and (b) larger second phase region, and (c) carbon content in austenite after the formation of polygonal ferrite, and bainitic ferrite and granular bainite. $R A$ is retained austenite, $S P R$ is second phase region, $P F$ is polygonal ferrite, $B F$ is bainitic ferrite and $G B$ is granular bainite.

When the fraction of the neighbouring PF is similar, the GB and BF should be further considered because the austenite is further enriched by their formation. The F1, B2 and B3 RA were in the same second phase region (Fig. 3) and thus they had the same fraction of neighbouring PF. B3 RA had a higher C content than B2 RA, despite B2 RA being close to the $\mathrm{PF} /$ second phase region interface, which expectedly leads to a shorter $\mathrm{C}$ diffusion distance 
from PF. This could be explained as follows. The B3 RA was present in GB, compared to the B2 RA, which was adjacent to ferrite in GB from one side and to PF from another side. Therefore, a larger interface area with ferrite in GB for B3 RA than that for B2 RA, led to more $\mathrm{C}$ atoms being rejected to B3 RA during GB formation. In addition, the size of B3 RA $(0.6 \mu \mathrm{m})$ is nearly half that of B2 RA $(1.1 \mu \mathrm{m})$, resulting in a higher C concentration in B3 RA. Comparison of film F1 and blocky B3 RA, shows that F1 RA exhibits higher C content. This is ascribed to a higher fraction of interface area for F1 RA surrounded by BF laths than that for the B3 RA present in GB, resulting in more $\mathrm{C}$ atoms rejected into the F1 RA.

Moreover, when cementite is adjacent to austenite, it will act as a $\mathrm{C}$ sink, leading to a decrease in the C content in austenite. Comparison of B4 and B5 RA shows that B5 RA has a lower $\mathrm{C}$ content even though its second phase region is smaller (Table 2), which is a result from the carbide formation adjacent to B5 RA (Fig. 6).

In addition to $\mathrm{C}$ enrichment, the RA was also enriched with Mn. However, the tendency for Mn enrichment in relation to the neighbouring phases was not so clear as for C (Table 2). For blocky RA, the Mn content had the same tendency as that for the C content with respect to the size of second phase region. The Mn content increased with a decrease in the size of second phase region because of more $\mathrm{Mn}$ atoms being rejected into remaining austenite from a larger fraction of neighbouring polygonal ferrite. When cementite formed, the Mn content decreased in RA (Fig. 6) due to the fact that Mn is a carbide-forming element. For film RA, the Mn content was between 1.68 and 1.95 at. \%, and showed no trend with respect to the size of second phase region and RA thickness. The Cr content was also enriched in RA compared with other phases (Table 2), but without any tendency in relation to neighbouring phases. Further APT-based characterisation is required to clarify this behaviour; however, such experiments are beyond the scope of the present study.

Following the above discussion with respect to the effect of neighbouring phases (PF, ferrite in GB, BF lath and cementite) on C content in RA, two general conclusions reported in the literature can be contested. Firstly, it has been previously reported that film RA has a higher C 
content than the blocky RA $[18,27,58]$. However, in the present site-specific atom scale characterisation, film F2 and F3 RA had a lower C content than all the observed blocky RA (Table 2). This unexpected low $\mathrm{C}$ content was due to the small fraction of neighbouring PF. Here the film F1 RA exhibited a higher C content than the blocky RA (B1 - B5 and A1) but a lower C content than the blocky A2 RA due to a different fraction of neighbouring PF. Secondly, there are reports that with a decrease in the RA thickness/size, the C content in RA increases [2, 9, 26, 27]. By contrast, in the present study, even though B4 RA had a larger ECD than B1 - B3 RA, the B4 RA had a higher C content (Table 2), again due to a larger fraction of neighbouring PF. However, when RA grains were in the same second phase region having the same fraction of neighbouring PF, comparison of F2 and F3, and B2 and B3, showed that smaller thickness and grain size leads to a higher $\mathrm{C}$ content.

$\mathrm{a}$

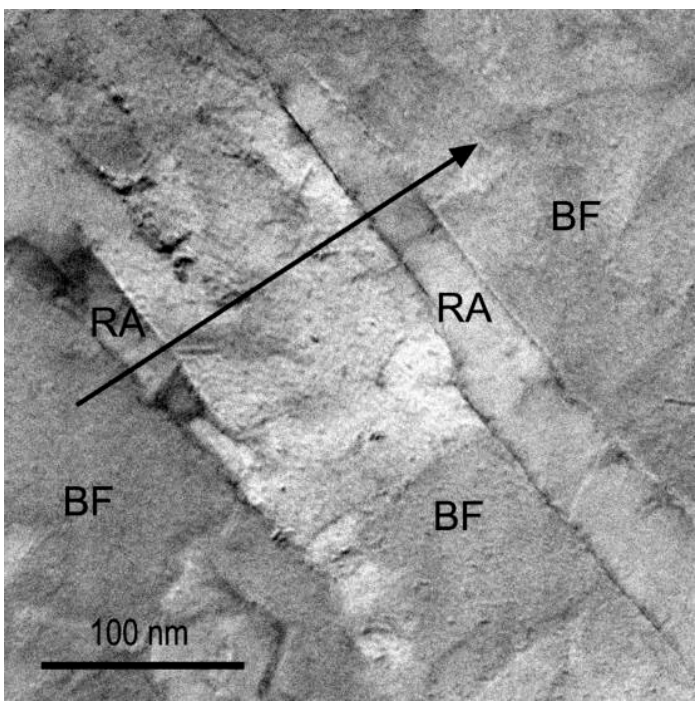

$\mathrm{b}$

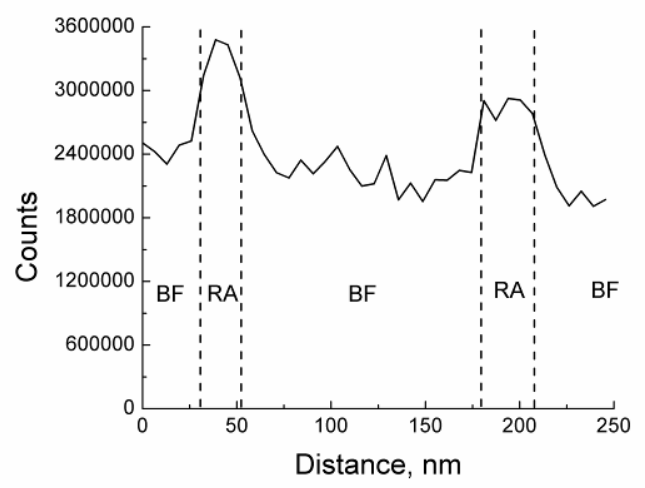

Figure 11. (a) TEM showing two film retained austenite and (b) corresponding carbon profile along the dark arrow in (a) using electron energy loss spectroscopy. $R A$ is retained austenite and $B F$ is bainitic ferrite lath.

Fig. 11 shows an EELS line scan across two film RA grains in the same second phase region, also indicating a relatively higher $C$ content in the thinner film RA $(\sim 44 \mathrm{~nm})$ than in the thicker one ( $55 \mathrm{~nm})$. This difference in C content of the two neighbouring film RA suggests that the $\mathrm{C}$ distribution at the nanoscale is quite heterogeneous. This has also been observed by Garcia-Mateo et al. [59] using APT where they reported wide variations in the C content of 
film RA in nanostructured bainitic steel, depending on film thickness. For $1-50 \mathrm{~nm}$ thick film RA, the C content ranged from 4.79 to 14.4 at. \%, while for film RA exceeding $50 \mathrm{~nm}$ the range was narrower from 4.77 to 6 at. \% C.

It is also well known that the neighbouring phases affect the RA stability $[2,14,19,60]$. The martensite start transformation temperature $\left(M_{s}\right)$ of the investigated RA crystals was calculated using the Andrew’s equation as follows [61]:

$$
M_{s}=539-423[\mathrm{C} \%]-30.4[\mathrm{Mn} \%]-11[\mathrm{Si} \%]-12.1[\mathrm{Cr} \%]
$$

where $[\mathrm{C} \%],[\mathrm{Mn} \%],[\mathrm{Si} \%]$ and $[\mathrm{Cr} \%]$ represent weight percentages of $\mathrm{C}, \mathrm{Mn}, \mathrm{Si}$ and $\mathrm{Cr}$, respectively. All calculated $M_{s}$ values (Table 2) are below room temperature except for F2 and F3 RA. The existence of these two film RA at room temperature could be explained by three-dimensional hydrostatic pressure which restricts the volume expansion and shear deformation from austenite-to-martensite transformation [22, 62]. This observation supports the idea that BF lath can strongly stabilise RA. In addition, the formation of Cottrell atmospheres in RA (Fig. 7(a)) also could contribute to its stabilisation by increasing the resistance of austenite transformation to martensite [60]. On the other hand, the high C content observed in the blocky RA enclosed by polygonal ferrite (A1 and A2 in Table 2) provides alternative support to the high stability of this RA during straining, which has been explained by stress relaxation delaying transformation [14].

\subsection{Bainite transformation mechanisms}

The debate regarding the mechanism of bainite transformation has been ongoing for a long time and is still not resolved. According to the displacive transformation mechanism, the $T_{o}$ curve (Fig. 12) is defined based on the condition that ferrite and austenite have the same chemical composition and the same free energy. The $T_{o}{ }^{\prime}$ curve is defined similar to the $T_{o}$ curve, with the additional consideration of the stored energy of the BF lath due to the displacive transformation $\left(400 \mathrm{~J} \cdot \mathrm{mol}^{-1}\right)$. The austenite-to-ferrite transformation line $\left(\mathrm{Ae}_{3}{ }^{\prime}\right)$ is calculated based on the PE model [29]. 
Fig. 12 displays the $\mathrm{C}$ contents in RA with respect to $T_{o}{ }^{\prime}, T_{o}$ and $A e_{3}$ 'measured locally (as a function of neighbouring phase) using APT and compared to an average value determined by XRD. Based on Fig. 12 (b), the $\mathrm{C}$ content can be categorized into three groups. The C content in the F2 film RA is lower than $T_{o}{ }^{\prime}$, indicating that it could further transform to ferrite. The $\mathrm{C}$ content in the F3 film RA is in-between $T_{o}^{\prime}$ and $T_{o}$, indicating the cessation of austenite-to-ferrite transformation. The rest of the RA contains a C content of $5.10-6.78$ at. \%, which is much higher than expected post-transformation at the locus of thermodynamic $T_{o}{ }^{\prime}(2.65$ at. \%). This is likely due to $\mathrm{C}$ partitioning during tempering after the completion of the bainite transformation. Another reason could be the inhomogeneous distribution of $\mathrm{C}$ between different austenite grains having different neighbouring phases (as discussed in section 4.2). This may allow transformation to continue to a larger extent than defined by the thermodynamic conditions based on the assumption of uniform $C$ distribution $[29,63]$. The $C$ content in RA did not reach the $\mathrm{Ae}_{3}{ }^{\prime}$ line due to the presence of Cottrell atmospheres (Fig. 7(a)) and cementite (Fig. 6). Also, the C contents in BF lath (0.53 \pm 0.02 at. \%) and ferrite in GB (0.54 \pm 0.02 wt. \%) were lower than the $T_{o}{ }^{\prime}$ limit, indicating carbon diffusion from ferrite to austenite during the $900 \mathrm{~s}$ holding at $400{ }^{\circ} \mathrm{C}$.

$\mathrm{a}$

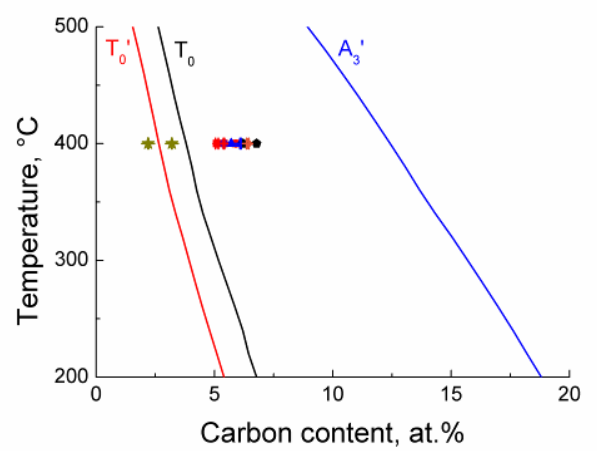

b

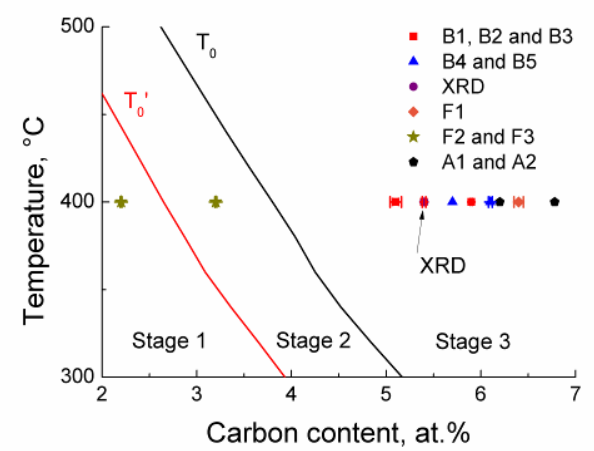

Figure 12. (a) Carbon content in retained austenite measured by atom probe tomography and X-ray diffraction and (b) a magnification of (a). $T_{o}, T_{o}$ ' and $A e_{3}$ ' are calculated according to http://www.msm.cam.ac.uk/map/steel/programs/mucg46-b.html.

Based on the above discussion, it can be concluded that the higher $\mathrm{C}$ content in RA and the lower $\mathrm{C}$ content in $\mathrm{BF}$ lath/ferrite in $\mathrm{GB}$ than $T_{o}{ }^{\prime}$ can be explained based on diffusionless 
transformation followed by tempering.

To this end, not only C partitioning between austenite and ferrite in GB/BF was detected in the current APT study, but also partitioning of Mn and to a lesser extent of Cr (Figs. 4 and 5). Only Mn segregation will be discussed in the following because of its clearly observed spikes.

a

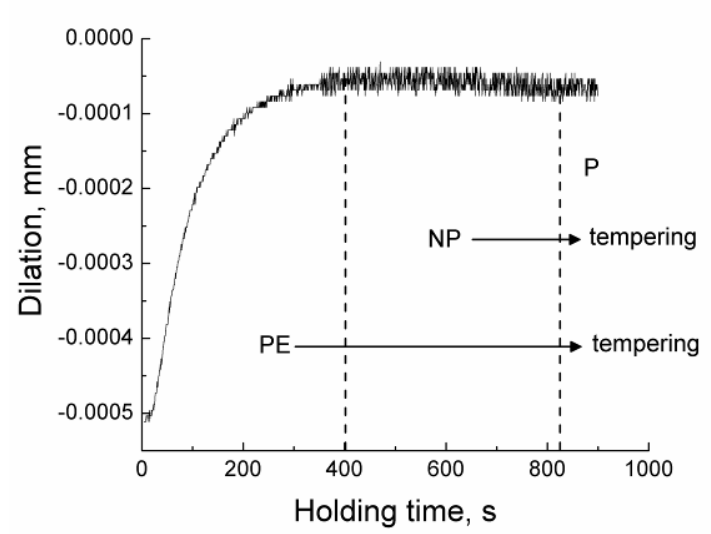

b

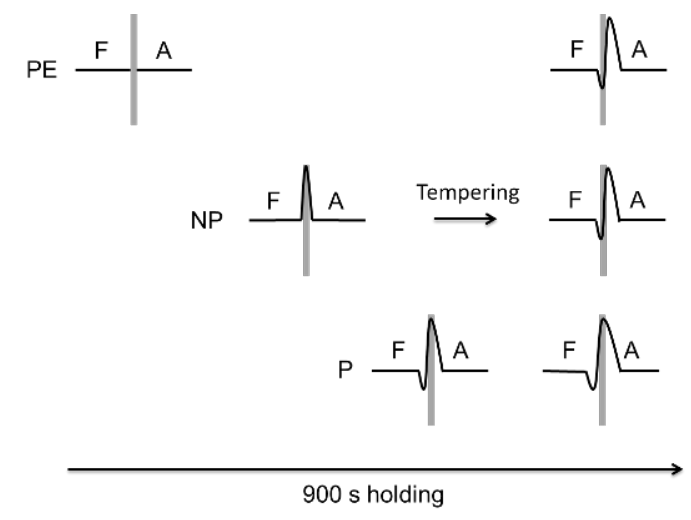

Figure 13. (a) Dilation as a function of holding time at $400{ }^{\circ} \mathrm{C}$ and (b) the corresponding evolution of segregation across the interface between austenite and ferrite after completion of growth (left diagrams) and after tempering (right schematics). $P E$ is paraequilibrium, $N P$ is negligible partitioning, $P$ is partitioning, $F$ is ferrite and $A$ is austenite.

Recently, the GEB approach was applied to analyse the bainite transformation based on the diffusional transformation mechanism involving substitutional solute partitioning [32, 33]. This approach predicts three growth models in the sequence of the PE, NP and P modes depending on the time of bainite nucleation during the IBT process [36]. These three growth models are schematically shown in relation to the dilation curve from the current work during $900 \mathrm{~s}$ holding at $400{ }^{\circ} \mathrm{C}$ (Fig. 13(a)), with the corresponding graphical representations of the substitutional solute partitioning (Fig. 13(b)). Within the first $200 \mathrm{~s}$ of holding, the kinetics of austenite-to-bainite transformation was fast and then became slower up to $\sim 400 \mathrm{~s}$, corresponding to the PE condition, where the segregation forms only during subsequent tempering. The transformation kinetics finally reached a plateau corresponding to the NP and P conditions, where the segregation occurs during the growth of bainite. If ferrite in GB/BF 
formed under NP condition (Fig. 13(a)), then substitutional element partitioning will also continue during tempering, and will be manifested by the slight shift of the peak formed at the interface to the austenite side. Since bainite formation under the $\mathrm{P}$ condition takes place at a later stage, the time for such a shift will be much less than that for the NP case and the location of the peak will be much closer to the interface, as depicted in Fig. 13(b).

According to the GEB model, the GB in the location B4 (Fig. 3(b)) should form under PE condition because of its early formation during the cooling to the IBT temperature. However, Mn segregation across the interface between austenite and ferrite in GB was observed in the present study (Fig. 5(e)). The ferrite nucleated in the PE transformation stage would grow without any substitutional solute segregation at/in the vicinity of the migrating austenite/ferrite interface [36]. Consequently, the observed segregation is expected to occur at the stationary austenite/ferrite interfaces upon tempering after growth completion under the PE condition (as illustrated in Fig. 13(b)). Similarly, Mn segregation occurring during tempering at $300{ }^{\circ} \mathrm{C}$ for $9 \mathrm{~h}$ was reported in a C-Mn-Si-Al TRIP steel [64].

The mean diffusion distance of Mn atoms can be calculated as [65]:

$d=\sqrt{D t}$

where $t$ is the holding time in seconds and $D$ is the diffusion coefficient. The volume diffusion coefficient of Mn atoms in the fcc iron matrix is expressed as follows [66]:

$D=1.78 \times 10^{-5} \exp (-Q / R T)$

where $Q$ is the activation energy (264000 J.mol $\left.{ }^{-1}\right), R$ is the universal gas constant (8.314 $\mathrm{J} \cdot \mathrm{mol}^{-1} \cdot \mathrm{K}^{-1}$ ) and $T$ is the temperature (in Kelvin). At $400{ }^{\circ} \mathrm{C}$ in the present study, the volume diffusion coefficient of Mn is calculated as $5.7 \times 10^{-26} \mathrm{~m}^{2} \cdot \mathrm{s}^{-1}$ using Eq. (5), which has the same order of magnitude to that in Ref. [67]. It is noted that the GB formed during cooling to the holding temperature. The build-up of $\mathrm{Mn}$ atoms at the interface between austenite and ferrite in GB is also assumed to occur during this cooling stage and subsequent isothermal holding after the growth of GB. This is due to the higher diffusion coefficient in ferrite than austenite by two orders of magnitude, leading to atomic jumps of Mn from the interface into the 
austenite [18, 67]. Thus, the diffusion time is set as $900 \mathrm{~s}$. According to Eq. (4), the mean diffusion distance of $\mathrm{Mn}$ atoms in the austenite is only $0.01 \mathrm{~nm}$, which is quite small diffusion compared with the distance of $1.1 \mathrm{~nm}$ measured by APT (Table 3).

However, pipe diffusion of Mn along dislocations should be considered due to the high dislocation density of ferrite lath/plate associated with shear transformation [27]. For instance, Dmitrieva et al. [24] reported an increase in the Mn diffusion coefficient by a factor of 45 during holding at $450{ }^{\circ} \mathrm{C}$ because of a pipe diffusion resulting from a high defect concentration in martensite lath. In addition, diffusion along grain boundaries also could accelerate this process [65]. Data regarding the Mn diffusion along dislocations or grain boundaries at low temperatures are scarce. Accordingly, the activation energy of $\mathrm{Mn}$ diffusion, which yields the measured diffusion distances of $1.1 \mathrm{~nm}$, was back calculated and the result was $0.79 Q$. Similarly, it was reported that the activation energy for $\mathrm{Cu}$ and $\mathrm{Nb}$ pipe diffusion is $0.73 Q$ [68] and $0.78 Q$ [69], respectively. Moreover, the activation energy for grain boundary diffusion is even smaller than that for pipe diffusion, such as $0.65 \mathrm{Q}$ for $\mathrm{Nb}$ [53]. Thus, it is possible that Mn atoms could diffuse over the measured distance of $1.1 \mathrm{~nm}$ during the $900 \mathrm{~s}$ holding at $400{ }^{\circ} \mathrm{C}$ by a combination of bulk, pipe and grain boundary diffusion.

As shown in Fig. 13(a), the PE condition finished at $\sim 400$ s. Therefore, the minimum time for $\mathrm{Mn}$ diffusion is $500 \mathrm{~s}$. Based on the estimated activation energy of $0.79 Q$, the corresponding minimum diffusion distance of $\mathrm{Mn}$ is calculated as $0.8 \mathrm{~nm}$. Therefore, the $\mathrm{Mn}$ diffusion distance of $1.0 \mathrm{~nm}$ on the austenite side across the lower interface between RA and the BF lath (Fig. 4 and Table 3) suggests this BF lath also formed under the PE condition. It is reasonable because this BF lath nucleated from the austenite grain boundary (as shown in Fig. 3(a)), which occurred at the beginning of the transformation. However, for the case of the upper interface between RA and BF lath (Fig. 4), the diffusion length of Mn on the austenite side is only $0.1 \mathrm{~nm}$, which is much shorter than the minimum diffusion distance for the PE condition. Thus, this BF lath could have formed under the NP condition followed by tempering, or just under the P condition. Furthermore, this means that the BF lath nucleated from a primary BF lath during holding [36], however, this cannot be seen in Fig. 3(a) 
probably due to its limited growth and subsequently small size. Seol et al. [18] also suggested the occurrence of $\mathrm{Mn}$ segregation across the interface between austenite and BF lath in Fe-0.71C-1.50Mn-1.5Si-0.5Al steel under the LENP condition (which is similar to NP condition [36]).

It is noted that regardless of the transformation mode of bainite, the substitutional solute segregation after tempering exhibits a similar profile (Fig. 13(b)). Therefore, the observed segregation by Seol et al. [18] also could be ascribed to tempering after BF lath formation under the PE condition instead of the LENP. Consequently, when the transformation model is determined only based on the segregation profile and corresponding modelling using DICTRA and Thermo-Calc software, these similar segregation profiles after tempering should be taken into consideration.

Noticeably, according to the diffusionless model and dilation curve (Fig. 13(a)), only diffusionless growth could take place during the first $\sim 400 \mathrm{~s}$ holding, followed by tempering during subsequent holding, which corresponds to the PE condition in the GEB approach based on diffusional mode. In both conditions, substitutional solutes do not partition during the growth of bainite but only partition during tempering after the completion of growth. For example, Pereloma et al. [28] and Caballero et al. [27] did not detect the segregation of substitutional solutes between RA and BF lath, which was taken as an evidence for diffusionless transformation of carbide-free bainite. Thus, the redistribution of Mn across the interface between RA and ferrite in GB (Fig. 5) and between RA and BF lath (lower interface in Fig. 4), which was ascribed to ferrite formation under the PE condition followed by tempering, could also be explained by diffusionless growth followed by tempering.

More importantly, the segregation of Mn across the RA/BF lath interface (upper interface in Fig. 4) can only be explained by ferrite formation under the NP or P conditions due to its small shift of $0.1 \mathrm{~nm}$ towards the austenite side, which is not consistent with the distance for the ferrite formation under PE condition or diffusionless growth followed by tempering. This indicates that bainite formation can be at least locally controlled by a diffusional mechanism, 
although this kind of segregation was only observed in one APT data set. Furthermore, there is a degree of uncertainty in the determination of the exact RA/BF interface in the APT data, due to the experimental error expected in such analysis. To reach a more convincing and definite answer, a series of further experiments on the segregation of Mn across the interface between austenite and ferrite in GB/BF during both early and late stages of bainite transformation are required.

\section{Conclusions}

Site-specific RA characterisation carried out by correlating EBSD, TEM and APT provided insights into the effect of neighbouring phases on the C content in RA and the substitutional solute segregation across interfaces.

(1) PF formation contributed more carbon to the neighbouring austenite than BF and GB formations. Carbon rejection to austenite was more efficient during BF formation than during GB formation due to a higher ratio of ferrite/ austenite interface area to the austenite volume for BF lath. However, adjacent to austenite, cementite acted as a carbon sink and resulted in a decrease in the carbon content in austenite.

(2) Two former ideas generally accepted in the literature are contested; namely, that blocky RA has a lower carbon content than film RA and that RA with a smaller size/thickness has a higher carbon content than coarser RA. It has been shown that the above two ideas are not necessarily always correct and instead the neighbouring phases of RA should be first taken into consideration.

(3) Despite that the calculated martensite transformation start temperatures $\left(147-241^{\circ} \mathrm{C}\right)$ was much higher than room temperature, film RA was stabilised at room temperature due to high hydrostatic pressure from BF laths.

(4) The diffusion of C and Mn could be explained based on either the diffusional mechanism under the PE, NP or P conditions and/or the diffusionless mechanism followed by tempering. 
Bainite formation under the NP or P condition suggests at least locally controlled diffusion of substitutional solutes across the austenite /BF lath interface.

\section{Acknowledgements}

This project was supported by the Australian Research Council (DP130101887). The JEOL JSM-7001F FEG-SEM and JEOL JEM-ARM200F were funded by the Australian Research Council (LE0882613 and LE120100104, respectively). The authors thank Drs. G. Casillas and D.R.G. Mitchell, University of Wollongong, for their help with the TEM and EELS observations, and Dr. A.V. Ceguerra, University of Sydney, AMMRF, for the fruitful discussions on the Gibbsian interfacial excess.

\section{References:}

[1] M. Takahashi, H. Bhadeshia, A model for the microstructure of some advanced bainitic steels. Materials Transactions, Mater. Trans. JIM 32 (1991) 689-696.

[2] E.V. Pereloma, A.A. Gazder, I.B. Timokhina, in: R. Colas, G.E. Totten (Eds.), Retained austenite: Transformation-Induced Plasticity, in Encyclopedia of Iron, Steel and their Alloys, Taylor and Francis, Inc. New York, 2016, pp. 3088-3103.

[3] B.C. De Cooman, Structure-properties relationship in TRIP steels containing carbide-free bainite, Curr. Opin. Solid State Mater. Sci. 8 (2004) 285-303.

[4] I.B. Timokhina, P.D. Hodgson, E.V. Pereloma, Effect of microstructure on the stability of retained austenite in transformation-induced-plasticity steels, Metall. Mater. Trans. A 35 A (2004) 2331-2341.

[5] F.G. Caballero, C. GarcíA-Mateo, J. Chao, M.J. Santofimia, C. Capdevila, C.G. De Andres, Effects of morphology and stability of retained austenite on the ductility of TRIP-aided bainitic steels, ISIJ Int. 48 (2008) 1256-1262.

[6] Y.F. Shen, L.N. Qiu, X. Sun, L. Zuo, P.K. Liaw, D. Raabe, Effects of retained austenite volume fraction, morphology, and carbon content on strength and ductility of nanostructured 
TRIP-assisted steels, Mater. Sci. Eng. A 636 (2015) 551-564.

[7] I. Timokhina, H. Beladi, X.Y. Xiong, Y. Adachi, P. Hodgson, Nanoscale microstructural characterization of a nanobainitic steel, Acta Mater. 59 (2011) 5511-5522.

[8] H.S. Park, J.C. Han, N.S. Lim, J.B. Seol, C.G. Park, Nano-scale observation on the transformation behavior and mechanical stability of individual retained austenite in CMnSiAl TRIP steels, Mater. Scie. Eng. A 627 (2015) 262-269.

[9] W. Li, H. Gao, H. Nakashima, S. Hata, W. Tian, In-situ EBSD study of deformation behavior of retained austenite in a low-carbon quenching and partitioning steel via uniaxial tensile tests, Mater. Charact. 118 (2016) 431-437.

[10] S. Kruijver, L. Zhao, J. Sietsma, S. Offerman, N. van Dijk, E. Lauridsen, L. Margulies, S. Grigull, H. Poulsen, S. van der Zwaag, In situ observations on the mechanical stability of austenite in TRIP-steel, J. Phys. IV 104 (2003) 499-502.

[11] C. Wang, H. Ding, M. Cai, B. Rolfe, Characterization of microstructures and tensile properties of TRIP-aided steels with different matrix microstructure, Mater. Sci. Eng. A 610 (2014) 65-75.

[12] E.V. Pereloma, A.A. Gazder, I.B. Timokhina, Addressing retained austenite stability in advanced high strength steels, Mater. Sci. Forum 738-739 (2013) 212-216.

[13] G.K. Tirumalasetty, M.A. van Huis, C. Kwakernaak, J. Sietsma, W.G. Sloof, H.W. Zandbergen, Unravelling the structural and chemical features influencing deformation-induced martensitic transformations in steels, Scripta Mater. 71 (2014) 29-32.

[14] Y. Tomota, H. Tokuda, Y. Adachi, M. Wakita, N. Minakawa, A. Moriai, Y. Morii, Tensile behavior of TRIP-aided multi-phase steels studied by in situ neutron diffraction, Acta Mater. 52 (2004) 5737-5745.

[15] K. Yan, K. Liss, I.B. Timokhina, E.V. Pereloma, In situ synchrotron X-ray diffraction studies of the effect of microstructure on tensile behavior and retained austenite stability of thermo-mechanically processed transformation induced plasticity steel, Mater. Sci. Eng. A 662 (2016) 185-197.

[16] R. Blondé, E. Jimenez-Melero, L. Zhao, J.P. Wright, E. Brück, S. van der Zwaag, N.H. van Dijk, Mechanical stability of individual austenite grains in TRIP steel studied by synchrotron X-ray diffraction during tensile loading, Mater. Sci. Eng. A 618 (2014) 280-287.

[17] E. Pereloma, I.B. Timokhina, M.K. Miller, P.D. Hodgson, Three-dimensional atom probe analysis of solute distribution in thermomechanically processed TRIP steels, Acta 
Mater. 55 (2007) 2587-2598.

[18] J. Seol, D. Raabe, P. Choi, Y. Im, C. Park, Atomic scale effects of alloying, partitioning, solute drag and austempering on the mechanical properties of high-carbon bainitic-austenitic TRIP steels, Acta Mater. 60 (2012) 6183-6199.

[19] X.C. Xiong, B. Chen, M.X. Huang, J.F. Wang, L. Wang, The effect of morphology on the stability of retained austenite in a quenched and partitioned steel, Scripta Mater. 68 (2013) 321-324.

[20] G. Reisner, E. Werner, P. Kerschbaummayr, I. Papst, F. Fischer, The modeling of retained austenite in low-alloyed TRIP steels, JOM 49 (1997) 62-65.

[21] G.K. Tirumalasetty, M.A. van Huis, C. Kwakernaak, J. Sietsma, W.G. Sloof, H.W. Zandbergen, Deformation-induced austenite grain rotation and transformation in TRIP-assisted steel, Acta Mater. 60 (2012) 1311-1321.

[22] K. Sugimoto, M. Misu, M. Kobayashi, H. Shirasawa, Effects of Second Phase Morphology on Retained Austenite Morphology and Tensile Properties in a TRIP-aided Dual-phase Steel Sheet, ISIJ Int. 33 (1993) 775-782.

[23] J. Chiang, J.D. Boyd, A.K. Pilkey, Effect of microstructure on retained austenite stability and tensile behaviour in an aluminum-alloyed TRIP steel, Mater. Sci. Eng. A 638 (2015) 132-142.

[24] O. Dmitrieva, D. Ponge, G. Inden, J. Millán, P. Choi, J. Sietsma, D. Raabe, Chemical gradients across phase boundaries between martensite and austenite in steel studied by atom probe tomography and simulation, Acta Mater. 59 (2011) 364-374.

[25] Y. Toji, H. Matsuda, M. Herbig, P. Choi, D. Raabe, Atomic-scale analysis of carbon partitioning between martensite and austenite by atom probe tomography and correlative transmission electron microscopy, Acta Mater. 65 (2014) 215-228.

[26] I.B. Timokhina, M.K. Miller, H. Beladi, P.D. Hodgson, The influence of fine ferrite formation on the $\gamma / \alpha$ interface, fine bainite and retained austenite in a thermomechanically-processed transformation induced plasticity steel, J. Mater. Res. 31 (2016) 806-818.

[27] F.G. Caballero, M.K. Miller, S.S. Babu, C. Garcia-Mateo, Atomic scale observations of bainite transformation in a high carbon high silicon steel, Acta Mater. 55 (2007) 381-390.

[28] E. Pereloma, H. Beladi, L. Zhang, I. Timokhina, Understanding the behavior of advanced high-strength steels using atom probe tomography, Metall. Mater. Trans. A 43 
(2012) 3958-3971.

[29] H.K.D.H. Bhadeshia, D.V. Edmonds, The mechanism of bainite formation in steels, Acta Metall. 28 (1980) 1265-1273.

[30] M. Hillert, L. Höglund, J. Ågren, Role of carbon and alloying elements in the formation of bainitic ferrite, Metall. Mater. Trans. A 35 (2004) 3693-3700.

[31] H.I. Aaronson, The Mechanism of Phase Transformations in Crystalline Solids, Institute of Metals, London, 1969.

[32] H. Chen, A. Borgenstam, J. Odqvist, I. Zuazo, M. Goune, J. Ågren, S. van der Zwaag, Application of interrupted cooling experiments to study the mechanism of bainitic ferrite formation in steels, Acta Mater. 61 (2013) 4512-4523.

[33] H. Chen, K. Zhu, L. Zhao, S. van der Zwaag, Analysis of transformation stasis during the isothermal bainitic ferrite formation in Fe-C-Mn and Fe-C-Mn-Si alloys, Acta Mater. 61 (2013) 5458-5468.

[34] H. Chen, S. van der Zwaag, Predicting the effect of Mo, Ni, and Si on the bainitic stasis, Metall. Mater. Trans. A 45 (2014) 3429-3437.

[35] H. Chen, Z. Yang, C. Zhang, K. Zhu, S. van der Zwaag, On the transition between grain boundary ferrite and bainitic ferrite in Fe-C-Mo and Fe-C-Mn alloys: The bay formation explained, Acta Mater. 104 (2016) 62-71.

[36] H. Chen, S. van der Zwaag, The Effect of Interfacial Element Partitioning on Ferrite and Bainite Formation, JOM 68 (2016) 1320-1328.

[37] L. Strezov, J. Herbertson, Experimental studies of interfacial heat transfer and initial solidification pertinent to strip casting, ISIJ Int. 38 (1998) 959-966.

[38] M. Ramajayam, N. Stanford, Static recrystallisation of steels produced by direct strip casting - The effect of carbon and vanadium concentration, Mater. Sci. Eng. A 671 (2016) 147-157.

[39] Z.P. Xiong, A.G. Kostryzhev, A.A. Saleh, L. Chen, E.V. Pereloma, Microstructures and mechanical properties of TRIP steel produced by strip casting simulated in the laboratory, Mater. Sci. Eng. A 664 (2016) 26-42.

[40] L.C. Chang, H.K.D.H. Bhadeshia, Austenite films in bainitic microstructures. Materials Science and Technology, Mater.Sci. Technol. 11 (1995) 874-882.

[41] K. Thompson, D. Lawrence, D. Larson, J. Olson, T. Kelly, B. Gorman, In situ 
site-specific specimen preparation for atom probe tomography, Ultramicroscopy 107 (2007) 131-139.

[42] P.J. Felfer, T. Alam, S.P. Ringer, J.M. Cairney, A reproducible method for damage-free site-specific preparation of atom probe tips from interfaces, Microsc. Res. Tech. 75 (2012) 484-491.

[43] M.K. Miller, Atom probe tomography: Analysis at the atomic level, Kluwer Academic/Plenum press, New York (NY), 2000.

[44] N. Takayama, G. Miyamoto, T. Furuhara, Effects of transformation temperature on variant pairing of bainitic ferrite in low carbon steel, Acta Mater. 60 (2012) 2387-2396.

[45] F. Meisenkothen, E.B. Steel, T.J. Prosa, K.T. Henry, R. Prakash Kolli, Effects of detector dead-time on quantitative analyses involving boron and multi-hit detection events in atom probe tomography, Ultramicroscopy 159 (2015) 101-111.

[46] F.G. Caballero, M.K. Miller, C. Garcia-Mateo, Opening previously impossible avenues for phase transformation in innovative steels by atom probe tomography, Mater. Sci. Technol. 30 (2014) 1034-1039.

[47] W. Owen, The effect of silicon on the kinetics of tempering, Trans. Am. Soc. Metals 46 (1954) 812-829.

[48] F.G. Caballero, Carbide-free bainitic steels, in: E.V. Pereloma, D.V. Edmonds (Eds.) Phase Transformations in Steels: Diffusionless Transformations, High Strength Steels, Modelling and Advanced Analytical Techniques, Woodhead Publishing Limited, 2012, pp. 436-467.

[49] F.G. Caballero, M.K. Miller, C. Garcia-Mateo, C. Capdevila, S.S. Babu, Redistribution of alloying elements during tempering of a nanocrystalline steel, Acta Mater. 56 (2008) 188-199.

[50] D. Kalish, M. Cohen, Structural changes and strengthening in the strain tempering of martensite, Mater. Sci. Eng. 6 (1970) 156-166.

[51] A.W. Cochardt, G. Schoek, H. Wiedersich, Interaction between dislocations and interstitial atoms in body-centered cubic metals, Acta Metall. 3 (1955) 533-537.

[52] I.B. Timokhina, H. Beladi, X. Xiong, P.D. Hodgson, On the low temperature strain aging of bainite in the TRIP steel, Metall. Mater. Trans. A 44 (2013) 5177-5191.

[53] B.W. Krakauer, D.N. Seidman, Absolute atomic-scale measurements of the Gibbsian interfacial excess of solute at internal interfaces, Phys. Rev. B 48 (1993) 6724. 
[54] E. Pereloma, Critical assessment 20: on carbon excess in bainitic ferrite, Mater. Sci. Technol. 32 (2016) 99-103.

[55] K. Tagashira, N. Sumita, H. Hayakawa, Effect of Si on the Formation of Mn-C Dipoles in Fe-Si-Mn-C Alloys, Mater. Trans. JIM 30 (1989) 10-18.

[56] Z.P. Xiong, A.G. Kostryzhev, L. Chen, E.V. Pereloma, Microstructure and mechanical properties of strip cast TRIP steel subjected to thermo-mechanical simulation, Mater. Sci. Eng. A 677 (2016) 356-366.

[57] F.G. Caballero, M.J. Santofimia, C. García-Mateo, J. Chao, C.G. de Andrés, Theoretical design and advanced microstructure in super high strength steels, Mater. Des. 30 (2009) 2077-2083.

[58] C. Garcia-Mateo, F.G. Caballero, M.K. Miller, J.A. Jimenez, On measurement of carbon content in retained austenite in a nanostructured bainitic steel, J. Mater. Sci. 47 (2012) 1004-1010.

[59] E.R. Morgan, T. Ko, Thermal stabilization of austenite in iron-carbon-nickel alloys, Acta Metall. 1 (1953) 36-48.

[60] K.W. Andrews, Empirical formulate for calculation of some transformation temperatures, J. Iron Steel Inst. London 203 (1965) 721-727.

[61] T. Sakaki, K. Sugimoto, T. Fukuzato, Role of internal stress for continuous yielding of dual-phase steels, Acta Metall. 31 (1983) 1737-1746.

[62] F.G. Caballero, C. Garcia-Mateo, M.J. Santofimia, M.K. Miller, C. García de Andrés, New experimental evidence on the incomplete transformation phenomenon in steel, Acta Mater. 57 (2009) 8-17.

[63] H. Park, J. Seol, N. Lim, S. Kim, C. Park, Study of the decomposition behavior of retained austenite and the partitioning of alloying elements during tempering in $\mathrm{CMnSiAl}$ TRIP steels, Mater. Des. 82 (2015) 173-180.

[64] S.V. Divinski, F. Hisker, Y. Kang, J. Lee, C. Herzig, Tracer diffusion of 63Ni in nano- $\gamma$-FeNi produced by powder metallurgical method: systematic investigations in the $C$, B, and A diffusion regimes, Interface Sci. 11 (2003) 67-80.

[65] Z. Li, Z. Yang, C. Zhang, Z. Liu, Influence of austenite deformation on ferrite growth in a Fe-C-Mn alloy, Mater. Sci. Eng. A 527 (2010) 4406-4411.

[66] J. Miettinen, Calculation of solidification-related thermophysical properties for steels, Metall. Mater. Trans. B 28 (1997) 281-297. 
[67] P.J. Othen, M.L. Jenkins, G.D.W. Smith, High-resolution electron microscopy studies of the structure of $\mathrm{Cu}$ precipitates in $\alpha$-Fe, Philos. Mag. A 70 (1994) 1-24.

[68] B. Dutta, E.J. Palmiere, C.M. Sellars, Modelling the kinetics of strain induced precipitation in Nb microalloyed steels, Acta Mater. 49 (2001) 785-794.

[69] I.B. Timokhina, M. Enomoto, M.K. Miller, E.V. Pereloma, Microstructure-property relationship in the thermomechanically processed C-Mn-Si-Nb-Al-(Mo) transformation-induced plasticity steels before and after prestraining and bake hardening treatment, Metall. Mater. Trans. A 43 (2012) 2473-2483. 